Cite this: DOI: $10.1039 / \mathrm{c0xx00000x}$

www.rsc.org/xxxxxx

ARTICLE TYPE

\title{
Cyclization Reactions of Bis(allenes) for the Synthesis of Polycarbo(hetero)cycles
}

\author{
Benito Alcaide, ${ }^{* a}$ Pedro Almendros, ${ }^{* b}$ and Cristina Aragoncillo ${ }^{* a}$ \\ Received (in $X X X, X X X)$ Xth $X X X X X X X X X 20 X X$, Accepted Xth $X X X X X X X X X 20 X X$ \\ DOI: 10.1039/b000000x
}

The chemistry of allenes is an appealing topic which fascinates chemists nowadays. Their reactivity and versatility makes this skeleton a useful moiety to create a great variety of structures depending on the functional groups attached and the reaction conditions used. Recently, there is a growing interest in the study of the reactivity of bis(allenes) inspired in the chemistry developed in simple allenes. In this review 10 a collection of examples of cyclization reactions of bis(allenes) is presented as well as the future perspectives. 


\section{Cite this: DOI: $10.1039 / \mathrm{c0xx00000x}$}

\section{Introduction}

During the last 25 years, chemists worldwide have focused their attention in the study of allenes. ${ }^{1}$ In fact, its beauty has been recognized in a diversity of allenic natural products, many of 5 them showing interesting or promising therapeutic activities. Nowadays, around 150 natural products containing an allenic or cumulenic structure have been identified. ${ }^{2}$ In the meantime, the reactivity of allenes has been studied. Thus, a lot of novel interesting reactivity patterns have been reported where chemo-, 10 regio- and diastereoselectivity issues have been addressed. Cycloaddition, cross-coupling and cycloisomerization reactions among others, have been carried out affording a huge collection of structures. As long as allenes are showing us their interesting reactivity, many strategies deal with the synthesis of allenic 15 derivatives. ${ }^{1 \mathrm{a}, 3}$ Recently, the synthesis of conjugated bis(allenes), and their rich chemistry have been revised and it will not be covered in the present overview. ${ }^{4}$ Thus, the intention of this review is to present the state of the art of the cyclization chemistry of non-conjugated bis(allenes), in order to give the 20 reader the future perspectives of this skeleton in Organic Synthesis. ${ }^{5}$ Our aim is to show how discoveries concerning the reactivity of simple allenes have served to inspire chemists to apply, extend and develop the chemistry of this family of bis(allenes). This review has been divided in two sections, 25 namely, cycloaddition ${ }^{6}$ and cyclization reactions. For each section, both the allene-allene reactivity and the interaction of the bis(allene) moiety with another functionality present in the same molecule are discussed.

\section{Cycloaddition reactions}

\section{${ }_{30} 2.1$ [2+2] Cycloaddition Reactions}

\subsubsection{Reactivity Allene-Allene}

The cyclobutane skeleton can be found in natural products. ${ }^{7}$ Besides, the inherent ring strain makes this alicyclic scaffold as an excellent molecular building block in Organic Synthesis for 35 the construction of different molecules. ${ }^{8}$ One of the most popular and ancient reaction of allenes is the $[2+2]$ cycloaddition. The interest on this cycloaddition is due to its applicability to obtain the cyclobutane or cyclobutene rings in a single step.

The inter- and intramolecular [2+2] cycloaddition of allenes with 40 alkenes and alkynes has been studied under photochemical, thermal and metal-catalyzed conditions, affording the corresponding cyclobutanes/cyclobutenes regioselectively in most cases. ${ }^{9}$ Because the thermal process is not allowed by the Woodward-Hoffmann rules ${ }^{10}$ and the Fukui's frontier oribital 45 theory, ${ }^{11}$ most of the examples have been explained via a stepwise diradical mechanism. However, when the reaction is catalyzed by a transition metal catalyst the reaction mechanism has been explained in terms of reductive elimination of metallacyclopentanes or metallacyclopentenes intermediates. On 50 the other hand, the regioselectivity has been controlled by the nature of the substituents attached to the allene moiety; however, in some cases it has been modulated by the reaction conditions. By resemblance with both enallenes and ynallenes, when we raise the study of the intramolecular [2+2] cycloaddition of 55 bis(allenes), is essential to consider the number of possible regioisomers, depending their formation of the $\pi$-component involved in the process. Then, if we use a symmetric bis(allene), four possible regioisomers can be formed, head-to-head, tail-totail, head-to tail and tail-to-head adducts (Scheme 1).

60

Scheme 1 Possible regioisomers formed in the intramolecular [2+2] cycloaddition of bis(allenes).

Recently, it has been studied the [2+2] cycloaddition of 1,5bis(allenes) 1 and 2 under both thermal and $\operatorname{Pd}(0)$-catalytic 65 conditions. This work has shown how the reaction conditions can control the regioselectivity of the final compounds independently of the structure of the starting materials. Thus, treatment of bis(allenes) $\mathbf{1}$ and $\mathbf{2}$ in toluene at reflux temperature afforded tailto-tail regioisomers $\mathbf{3}$ in moderate to good yields. ${ }^{12}$ It has been 70 observed that the reaction is very sensitive to dilution, founding that the optimal conditions were the use of a $0.04 \mathrm{M}$ solution of compounds 1 in refluxed xylene. On the other hand, substituted allenes gave better yields due to stabilization of the presumable radical intermediates involved in the reaction. In addition, a very 75 bulky $\mathrm{X}$ group, such as $\mathrm{C}\left(\mathrm{CO}_{2} \mathrm{Me}\right)_{2}$ and $\mathrm{C}\left(\mathrm{SO}_{2} \mathrm{Ph}\right)_{2}$ instead of $\mathrm{N}$ Ts, makes both allene functionalities closer favouring the [2+2] cycloaddition according to the Thorpe-Ingold effect, increasing the yields of compounds 3 from 43 to $74 \%$ (Scheme 2).

Formation of fused strained bicycles 3 could be rationalized by a 80 mechanism that includes an exocyclic diradical intermediate $\mathbf{4 a}$, through initial carbon-carbon bond formation involving the central carbon of both allenes moieties (Scheme 3). An alternative pathway for this thermal cycloaddition would involve an endocyclic diradical intermediate $\mathbf{4} \mathbf{b}$, arising from the initial 
attack of the distal carbons of both allenes. For both cases, the final step must involve a rapid ring closure of the diradical intermediates before bond rotation can occur. Although there is no evidence of which of both proposed alternatives is the truly 5 mechanism, it seems possible that the substituents $\mathrm{R}^{1}$ and $\mathrm{R}^{2}$ must stabilize the exocyclic diradical, promoting the bis(allylic) radical 4a over the alternate endocyclic vinylic radical $\mathbf{4 b}$.
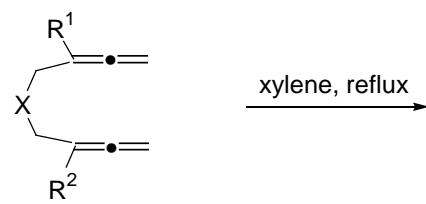
1a, $R^{1}=R^{2}=H, X=N T S$
1b, $\mathrm{R}^{1}=\mathrm{R}^{2}=\mathrm{H}, \mathrm{X}=\mathrm{C}\left(\mathrm{SO}_{2} \mathrm{Ph}\right)_{2}$
1c, $R^{1}=R^{2}=\mathrm{H}, X=C\left(\mathrm{CO}_{2} \mathrm{Et}\right)_{2}$
1d, $\mathrm{R}^{1}=\mathrm{R}^{2}=\mathrm{H}, \mathrm{X}=\mathrm{C}\left(\mathrm{CO}_{2} \mathrm{Me}\right)\left(\mathrm{SO}_{2} \mathrm{Ph}\right)$
2a, $\mathrm{R}^{1}=\mathrm{R}^{2}=\mathrm{Et}, \mathrm{X}=\mathrm{C}\left(\mathrm{SO}_{2} \mathrm{Ph}\right)_{2}$
2b, $\mathrm{R}^{1}=\mathrm{R}^{2}=\mathrm{Et}, \mathrm{X}=\mathrm{C}\left(\mathrm{CO}_{2} \mathrm{Me}\right)_{2}$
2c, $\mathrm{R}^{1}=\mathrm{Me}, \mathrm{R}^{2}=\mathrm{H}, \mathrm{X}=\mathrm{C}\left(\mathrm{SO}_{2} \mathrm{Ph}\right)_{2}$

\begin{abstract}
3a, $43 \%$
3b, $61 \%$

3c, $38 \%$

3d, $61 \%$

3e, $74 \%$

3f, $70 \%$

3g, $69 \%$
\end{abstract}

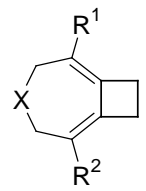

10 Scheme 2 Thermal intramolecular [2+2] cycloaddition of bis(allenes) 1a-d and $\mathbf{2 a - c}$

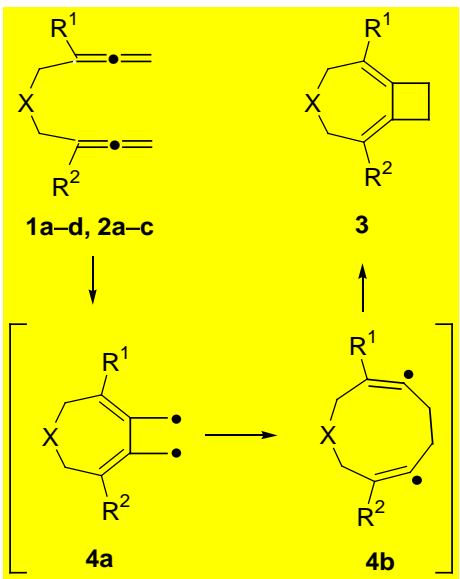

Scheme 3 Mechanistic proposal for the thermal intramolecular [2+2] cycloaddition of bis(allenes) $\mathbf{1}$ and $\mathbf{2}$.

15 Interestingly, when the same substrates, bis(allenes) 1a-c, where treated under palladium catalysis, head-to-head bicyclic cyclobutanes 5 were obtained instead (Scheme 4). Furthermore, reaction of compound 1e, containing the chiral L-valine ester moiety, under the same metal-catalytic conditions, gave 20 compound $5 \mathbf{d}$ without racemization of the $\alpha$-amino ester. By contrast with the thermal [2+2] cycloaddition, which takes place via diradical intermediates, when the $[2+2]$ cycloaddition is performed with transition metal catalysts, the process is explained in terms of the reductive elimination of metallacyclopentanes $\mathbf{6}$ as 25 the key step in the formation of the four-membered rings (Scheme 4). Interestingly, the use of $\mathrm{K}_{2} \mathrm{CO}_{3}$ and $n \mathrm{Bu}_{4} \mathrm{NI}$ are both essential to obtain cyclobutanes 5. Presumably, $n \mathrm{Bu}_{4} \mathrm{NI}$ must facilitate the reductive elimination step.
30 Scheme $4 \mathrm{Pd}(0)$-catalyzed intramolecular [2+2] cycloaddition of bis(allenes) 1.

A plausible model for the highly diastereoselective $\mathrm{Pd}(0)$ catalyzed [2+2] cycloaddition of 1,5-bis(allenyl) compound $\mathbf{1 e}$ is shown in Scheme 5. Coordination between the Pd atom and the 35 lone pair of electrons of the $\mathrm{N}$ atom in intermediate 7 , along with the requirement of the $\mathrm{Pd}$ atom to be distant from the bulkier $\mathrm{CO}_{2} \mathrm{Et}$ group, would lead to the exclusive formation of $\mathbf{5 d}$. The inversion of the nitrogen center may be very difficult in this case because of the presence of the bicyclic skeleton. In addition, this 40 model would explain why the formation of the head-to-head regioisomer $\mathbf{5}$ is favored over the tail-to-tail regioisomer observed under thermal conditions. If the coordination between Pd atom would involve the external double bond of both allene moieties, coordination with the lone pair of the nitrogen atom would not be 45 possible.

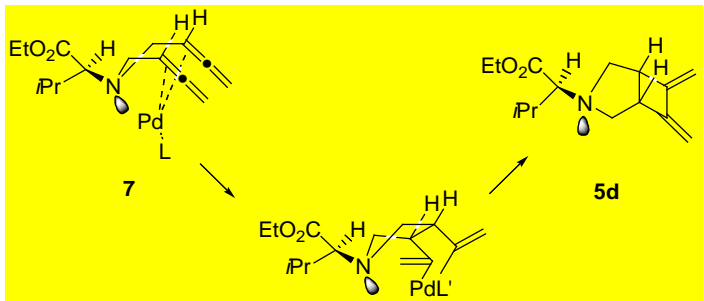

Scheme 5 Explanation of the highly diastereoselective $\operatorname{Pd}(0)$ catalyzed [2+2] cycloaddition of bis(allene) $\mathbf{1 e}$.

In some cases it is possible to predict the regiochemistry of the 50 [2+2] cycloaddition, in particular when the formation of a more stable ring is favored than another one. For example, recently, [2+2] cycloaddition of 1,4-bis(allenes) $\mathbf{8}$ has been studied. Interestingly, treatment of compound $\mathbf{8}$ under thermal conditions gave [3,3]-sigmatropic rearrangement product $\mathbf{9}$ as major product 55 and the desired [2+2] cycloadduct $\mathbf{1 0}$ in low yield. ${ }^{13}$ After testing different reaction conditions using $\mathrm{Mo}(\mathrm{CO})_{6}, \mathrm{PdCl}_{2}\left(\mathrm{PPh}_{3}\right)_{2}$ and $\mathrm{Pd}\left(\mathrm{PPh}_{3}\right)_{4}$ as transition metal catalysts, the authors found that the combination of $\mathrm{CuBr}_{2}$ and $i \mathrm{Pr}_{2} \mathrm{NH}$ afforded the corresponding 
[2+2] product $\mathbf{1 0}$ in good yields, minimizing the formation of compound 9 (Scheme 6). Different substitution in the tether as well as on the allene moiety was well tolerated. The process was investigated through a one-pot protocol from the corresponding 5 1,4-bis(alkynes) 11, using Crabbé homologation conditions. Interestingly, compounds $\mathbf{1 0}$ were obtained in moderate yields. Although the authors did not present mechanistic details, it is presume that the [2+2] cycloaddition takes place via formation of a cupracyclopentane 12. Clearly, formation of the tail-to-tail 10 regioisomer is favoured over the corresponding head-to-head isomer due to the formation of a six-membered ring fused to a cyclobutane.

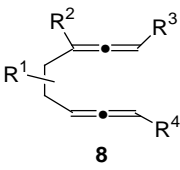

$\mathrm{R}^{1}=\mathrm{H}$, alkyl, aryl, alkoxy $R^{2}, R^{3}, R^{4}=H$, alkyl

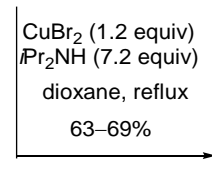<smiles>[R1]C1=C2CCC=C(C1[R])C2[R]</smiles>

10<smiles>[R]C1=C2C(=CC1)C([R])C(CI)C2[R]</smiles><smiles>[R]C=C([R])C(=C[R])C(C=C)=C[R]</smiles>

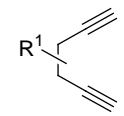

11

$\mathrm{R}^{2}=\mathrm{R}^{3}=\mathrm{R}^{4}=\mathrm{H}$

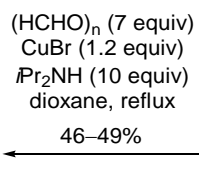

Scheme 6 Cu-promoted intramolecular [2+2] cycloaddition of 15 bis(allenes) 8.

On the other hand, sigmatropic rearrangements are the second most important synthetic methodology to obtain allenes, after prototropic isomerizations. This methodology has taken 20 advantage to prepare bis(allenes) via double [2,3] sigmatropic rearrangements of propargyl sulfenates and propargyl sulfinates to afford allenic sulfoxides and sulfones, respectively. In fact, in an early example, it was studied the [2+2] cycloaddition of bis(allenes), generated in situ from enediynediols, to afford 25 cyclobutane-fused arenes under thermal conditions. Thus, compound 13 by treatment with $\mathrm{SOCl}_{2}$ rearranges to form bis(allene) intermediate 14, which after thermal cyclization leads to 15 (Scheme 7). ${ }^{14}$ Reaction of compound 16 with $\mathrm{Pd}(0)-\mathrm{SmI}_{2}$ followed by ring closure, afforded adduct 17 (mixture of trans30 and cis; 84:16) via a [2+2] cycloaddition in 66\% yield, involving intermediate bis(allene) $\mathbf{1 8} .{ }^{15}$ When the reaction was performed at $-30^{\circ} \mathrm{C}$ and the mixture was stirred at room temperature for several hours, the diastereoselectivity was improved (trans:cis = 98:2) while the yield just slightly decreased (59\%). Formation of 35 both cycloadducts $\mathbf{1 5}$ and $\mathbf{1 7}$ is preferred over the corresponding head-to-head isomers due to the size of the ring formed and the aromaticity observed in the final cycloadducts.

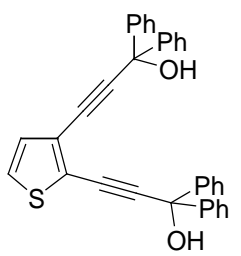

13

$\mid \begin{gathered}\mathrm{SOCl}_{2} \\ \Delta\end{gathered}$<smiles>ClC(=C=C(Cl)c1ccsc1C=Cc1ccccc1)c1ccccc1</smiles>

14<smiles>Clc1c2c(c(Cl)c3sccc13)C(c1ccccc1)(c1ccccc1)C2(c1ccccc1)c1ccccc1</smiles>

15

$97 \%$<smiles>CC(=O)OC(C#CC(OC(C)=O)c1ccccc1)c1ccccc1</smiles>

16<smiles>C(=Cc1ccccc1C=Cc1ccccc1)c1ccccc1</smiles>

18<smiles>c1ccc([C@@H]2c3cc4ccccc4cc3[C@H]2c2ccccc2)cc1</smiles>

17
RT to $65^{\circ} \mathrm{C}, 66 \%$, trans: cis $=84: 16$

$-30^{\circ} \mathrm{C}$ to $\mathrm{RT}, 59 \%$, trans:cis $=98: 2$

Scheme 7 Intramolecular [2+2] cycloaddition of in situ generated 40 bis(allenes) 14 and 18.

Thus, when the aromaticity of the final compound is the driving force of the process, it is easy to predict which regioisomer would be observed.

45 This behaviour has been observed in a more recent work. The synthesis of anthracyclobutene derivatives 19 via crystal-tocrystal thermal [2+2] cycloaddition of compounds 20, involving bis(allene) intermediates $\mathbf{2 1}$ has been reported (Scheme 8). ${ }^{16}$ Probably, rotation of the bulky diarylallene groups is necessary 50 for the cyclization reaction.

Analogously, propargyl phosphites and propargyl phosphinates are also feasible substrates to obtain allenes via [2,3] sigmatropic rearrangement. Thus, benzene-bis(phosphinylallenes), derived from benzene-bis(propargyl alcohols) and 55 chlorodialkylphosphines, underwent intramolecular [2+2] cycloaddition leading to naptho[b]cyclobutenes. ${ }^{17}$ It has been postulated that dual [2,3]-sigmatropic rearrangement of the bis(alkynols) 22 takes place, giving 1,2-bis $(\alpha$ phosphinylallenyl)benzenes 23, which spontaneously undergo 60 intramolecular [2+2] cycloaddition to afford compounds 24 in excellent yields (Scheme 9). 


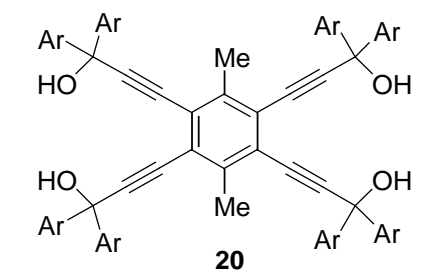

$\mathrm{Ar}=\mathrm{Ph}, 4-\mathrm{MeC}_{6} \mathrm{H}_{4}, 4-\mathrm{FC}_{6} \mathrm{H}_{4}, 4-\mathrm{ClC}_{6} \mathrm{H}_{4}$<smiles>C1C[SeH2]C1</smiles>

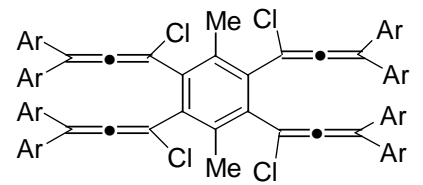

21

$$
\downarrow \begin{gathered}
\Delta \\
\text { solid }
\end{gathered}
$$

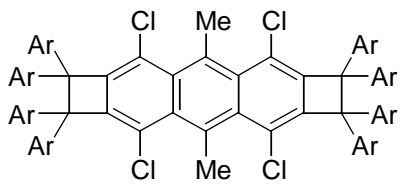

19, quantitative yield

Scheme 8 Crystal-to-cristal thermal [2+2] cycloaddition of compounds 21.
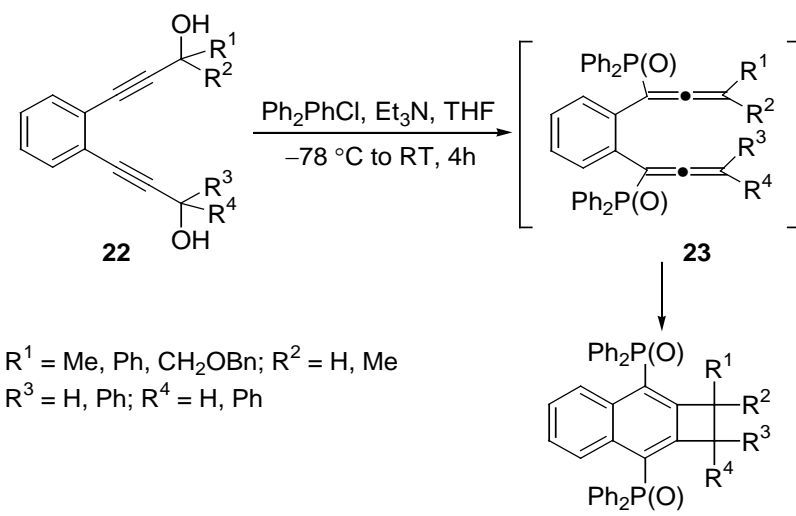

24

$84-90 \%$

5 Scheme 9 Intramolecular [2+2] cycloaddition of bis(phosphinylallenes) 23.

Formation of compounds $\mathbf{2 4}$ has been rationalized via the intermediacy of diradical intermediates $\mathbf{2 5}$ as shown in Scheme 10. The bis(phosphinylallenes) 23, derived from the 10 corresponding bis(propargylicphosphinites) by [2,3]-sigmatropic rearrangement, would be converted into the diradical species $\mathbf{2 5}$, which subsequently undergo ring closure to produce tricycles $\mathbf{2 4}$. The aromaticity of the final products is also a remarkable feature in the regiochemistry observed of the [2+2] cycloaddition, and is 15 probably the driving force to obtain compounds $\mathbf{2 4}$ as sole regioisomers.

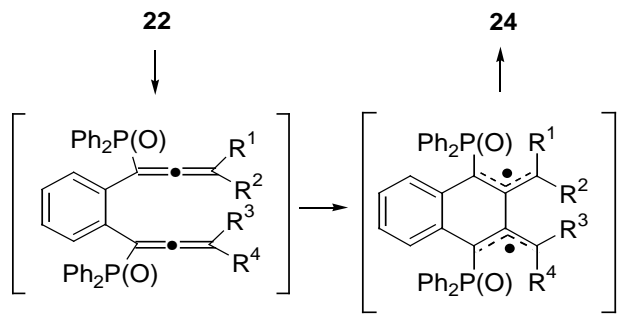

23

25

Scheme 10 Mechanistic explanation for the synthesis of compounds 24 20 via the intermediacy of bis(allenes) intermediates 23.

In the same context, it has been reported the titanium-mediated intramolecular cyclization of bis(allenes), prepared from bis(propargylic alcohol) derivatives, affording bicyclic cyclobutenes bearing six-and seven-membered rings. ${ }^{18}$ Treatment 25 of tethered bis(propargyl alcohol) derivatives $\mathbf{2 6}$ with titanium complex ( $\eta^{2}$-propene) Ti(O-i-Pr $)_{2}$, generated in situ by treatment of $\mathrm{Ti}(\mathrm{O}-i-\mathrm{Pr})_{4}$ with two equivalents of $i$-PrMgCl, allowed the formation of titanacycles $\mathbf{2 7}$ via cyclometalation. Elimination of the methoxy group with concomitant demetallation generated 30 bis(allenes) intermediates 28, which after formal [2+2] cycloaddition gave bicyclic cyclobutenes $\mathbf{2 9}$ in low to good yields (Scheme 11).

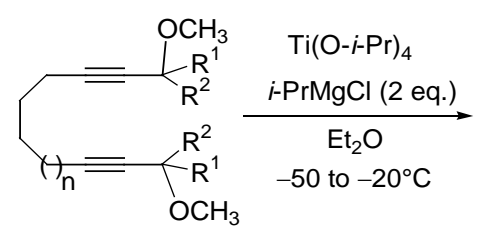

26

$\mathrm{n}=1,2$

$\mathrm{R}^{1}=\mathrm{H}, \mathrm{Me}$

$\mathrm{R}^{2}=\mathrm{H}, \mathrm{Ph}, n-\mathrm{C}_{5} \mathrm{H}_{11}$<smiles>[R]C([R])=C1C([R])=C2C3=[Ge]CCCC3=C1C2[R]</smiles>

29

$15-85 \%$

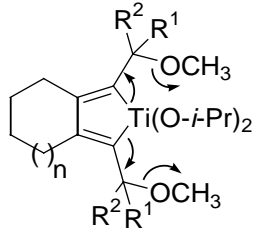

27<smiles>[R]C([R])=CC1=[Te]CCC/C1=C\C([R])[R]</smiles>

28
Scheme 11 Intramolecular cyclization of bis(allenes) 28.

35 1,7-Diyn-3,6-bis(propargyl carbonates) 30 may undergo cycloisomerization under gold-catalyzed conditions affording naphtha[b]cyclobutenes 31 (Scheme 12). ${ }^{19}$ The process involves the generation of bis(allenyl carbonate) $\mathbf{3 2}$ as key intermediates, which are ideal substrates to react via [2+2] cycloaddition of both 40 allene moieties. After testing different gold complexes, the authors found that the use of $\mathrm{PPh}_{3} \mathrm{AuCl}(5 \mathrm{~mol} \%$ ) in combination 
with $\mathrm{AgSBF}_{6}$ (5 mol\%) in THF at room temperature were the optimum reaction conditions. The scope of this cycloisomerization reaction has been investigated using a variety of aromatic substituents in the terminal alkyne position. The 5 electronic nature of the aromatic rings did not have a strong influence on this reaction. In fact, both electron-deficient and electron-rich substituents were tolerated during the reaction.

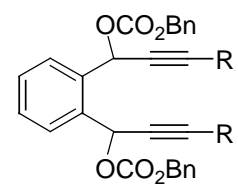

30

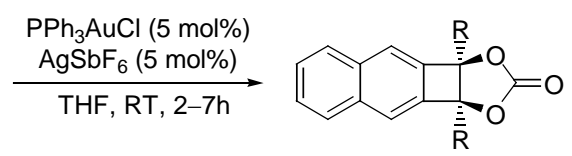

31
$\mathrm{R}=\mathrm{Ph}, p-\mathrm{Cl}-\mathrm{C}_{6} \mathrm{H}_{4}, p-\mathrm{Br}-\mathrm{C}_{6} \mathrm{H}_{4}, o-\mathrm{Br}-\mathrm{C}_{6} \mathrm{H}_{4}$ $p-\mathrm{F}-\mathrm{C}_{6} \mathrm{H}_{4}, p-\mathrm{CF}_{3}-\mathrm{C}_{6} \mathrm{H}_{4}, p-\mathrm{CO}_{2} \mathrm{Et}_{-} \mathrm{C}_{6} \mathrm{H}_{4}$, $p-\mathrm{Me}-\mathrm{C}_{6} \mathrm{H}_{4}, p-t \mathrm{Bu}-\mathrm{C}_{6} \mathrm{H}_{4}, p-\mathrm{MeO}-\mathrm{C}_{6} \mathrm{H}_{4}$<smiles>[R]C(=C=Cc1ccccc1C=CCCCCCCOC(=O)OCc1ccccc1)OC(=O)OCc1ccccc1</smiles>

10 Scheme 12 Synthesis of functionalized naphtha[b]-cyclobutanes $\mathbf{3 1}$ from 1,7-dyin-3,6-bis(propargyl carbonates) $\mathbf{3 0}$ involving bis(allene) intermediates 32.

Formation of compounds $\mathbf{3 1}$ is explained in Scheme 13 and involves a double 3,3-rearrangement reaction through the 15 nucleophilic attack of the benzyloxycarbonyl group on the gold(I)-activated alkyne moiety leading to the formation of the bis(allenyl carbonate) 32. Next, $6 \pi$-electrocyclic reaction would deliver species $\mathbf{3 3}$, which can be represented by the resonance structure 34, a highly stabilized biradical. Then, intermediates 33 20 and $\mathbf{3 4}$ would undergo cyclization to provide dicarbonates $\mathbf{3 5}$. Gold-assisted C-O bond cleavage would take place to give a benzylic cation intermediate $\mathbf{3 6}$. Subsequent ring-closure proceed by attack of the benzyloxycarbonyl group from the top side, which furnishes exclusively cis-31 (Path A). An alternative 25 pathway could be proposed, involving intramolecular nucleophilic attack of the allene moiety on the gold-activated allene $\mathbf{3 7}$ to form an oxocarbenium ion intermediate $\mathbf{3 8}$. Subsequent nucleophilic attack of the $\mathrm{Au}-\mathrm{C}\left(\mathrm{sp}^{3}\right)$ bond on the carbonyl moiety of the oxocarbenium ion would give the same 30 dicarbonate 32 (Path $B$ ).

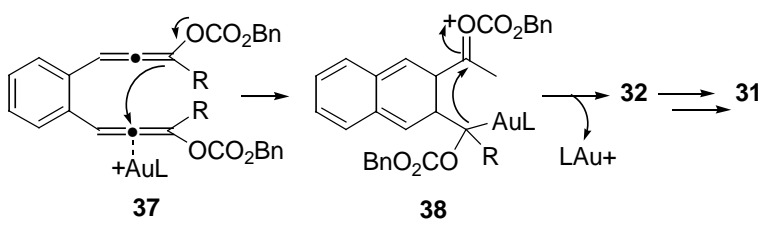<smiles>[R]C(OCc1ccccc1)=c1cc2ccccc2c/c1=C(\OC(=O)OCc1ccccc1)C(=O)OCc1ccccc1</smiles>

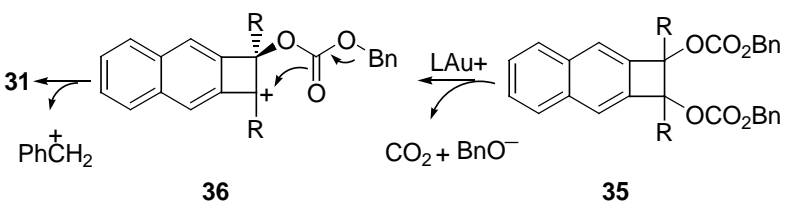

Scheme 13 Mechanistic explanation for the synthesis of compounds 31 involving bis(allenes) intermediates 32.

\subsubsection{Reactivity Allene-Alkyne}

35 Most of the [2+2] cycloaddition reactions of bis(allenes) reported so far involve the cycloaddition of two $\pi$-bonds of both allene moieties. However, in some cases, when the approximation of both allene moieties is not possible due the conformational disposition of the molecule, one allene fragment is susceptible to 40 react with a more proximal functionality. For example, recently it has been studied the double [2+2] cycloaddition between an alkyne and an allene moieties from bis(allene)-bis(alkyne) compounds, affording fused bicyclic adducts bearing a cyclobutene ring. This process takes place via palladium45 catalyzed or copper-promoted domino alkyne homocoupling/double $[2+2]$ allenyne cycloaddition. ${ }^{20}$ Interestingly, treatment of ynallenes 39 in presence of $\mathrm{PdCl}_{2}(2$ mol \%) and CuI (2 mol \%) afforded bis(dihydropyran-fused cyclobutenes) $\mathbf{4 0}$ in moderate yields (Scheme 14). In order to 50 study the scope of the reaction, 2-azetidinone-tethered ynallenes 41 were tested under the same reaction conditions. However, the $\mathrm{Pd}-\mathrm{Cu}$ bimetallic catalytic system failed to give the desired product even when the reaction temperature rose to $80^{\circ} \mathrm{C}$. Fortunately, when a stoichiometric amount of copper salt was 55 used the homodimerization/[2+2] bis(cycloaddition) sequence proceeded smoothly to afford enantiopure attached-ring bis(tricyclic) $\beta$-lactams 42 in good yields (Scheme 15).

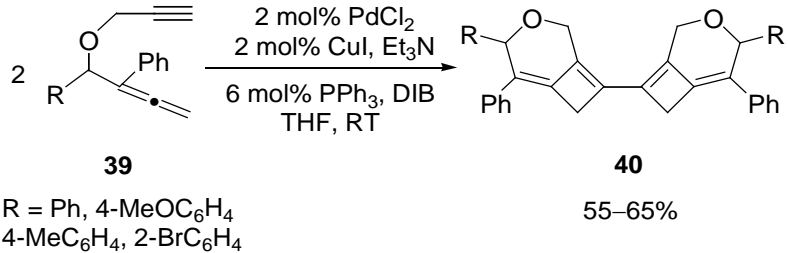

60 Scheme 14 Palladium-catalyzed or copper-promoted domino alkyne homocoupling/double [2+2] allenyne cycloaddition of ynallenes 39 . 


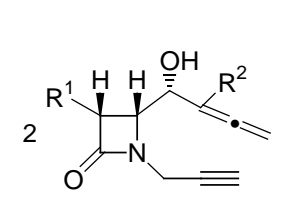

41

$\mathrm{R}^{1}=\mathrm{MeO}, \mathrm{PhO}$

$\mathrm{R}^{2}=\mathrm{Ph}, 4-\mathrm{MeOC}_{6} \mathrm{H}_{4}$

Scheme 15 Copper-promoted domino alkyne homocoupling/double [2+2] allenyne cycloaddition of azetidinone-tethered ynallenes $\mathbf{4 1}$.

5 A tentative mechanistic proposal for the metal-promoted alkyne homocoupling/[2+2] allenyne bis(cycloaddition) of allenynes is depicted in Scheme 16. It may involve the formation of dialkynylpalladium complexes of type $\mathbf{4 3}$ or copper(I) acetylides of type 44, which are then transformed into the corresponding 10 diynes 45. For the double [2+2] allenyne cycloaddition, it is believed that initially the metal salt regioselectively forms a $\pi$ complex with both the triple bond and the double bond of substrates 45 . Such $\pi$ complexes may undergo migratory C-C coupling to give pallada- or cupracyclopentenes of type $\mathbf{4 6}$.

${ }_{15}$ Following this step, intermediates $\mathbf{4 6}$ would undergo rapid reductive elimination to give bis(cyclobutenes) $\mathbf{4 0}$ and $\mathbf{4 2}$ as the final products. The observed high regioselectivity of the reaction could be explained in terms of the regioselective formation of metallacycles of type $\mathbf{4 6}$, which would be controlled by the 20 stereoelectronic effects of the aryl substituents $\left(R^{2}\right)$ in allenynes 39 and 41. Cyclization towards the internal allenic double bonds is probably restricted by the steric hindrance between the metal ligand moiety and the aryl substituent at the quaternary stereocenter.

25 Later on, a related synthesis of bis(tricycles) from bis( $\beta$-lactamallenynes) via double intramolecular [2+2] cycloaddition under thermal conditions has been reported. ${ }^{21}$ The starting materials, $C_{2}$-symmetric bis( $\beta$-lactam-allenynes) 47 and unsymmetrical allenynes 48 have been prepared via homodimerization reaction 30 using modified classical copper-promoted conditions and coppercatalyzed Cadiot-Chodkiewicz cross-copuling reaction, respectively. Treatment of compounds $\mathbf{4 7}$ and $\mathbf{4 8}$ under thermal conditions afforded $C_{2}$-symmetric attached-ring bis(tricyclic) $\beta$ lactams 42 and unsymmetrical bis(tricycles) 49 by a double [2+2] 35 allenyne cyclization (Scheme 17). It is interesting to observe that the reaction was completely regioselective and only depicted distal cycloadducts were the isolated isomers.

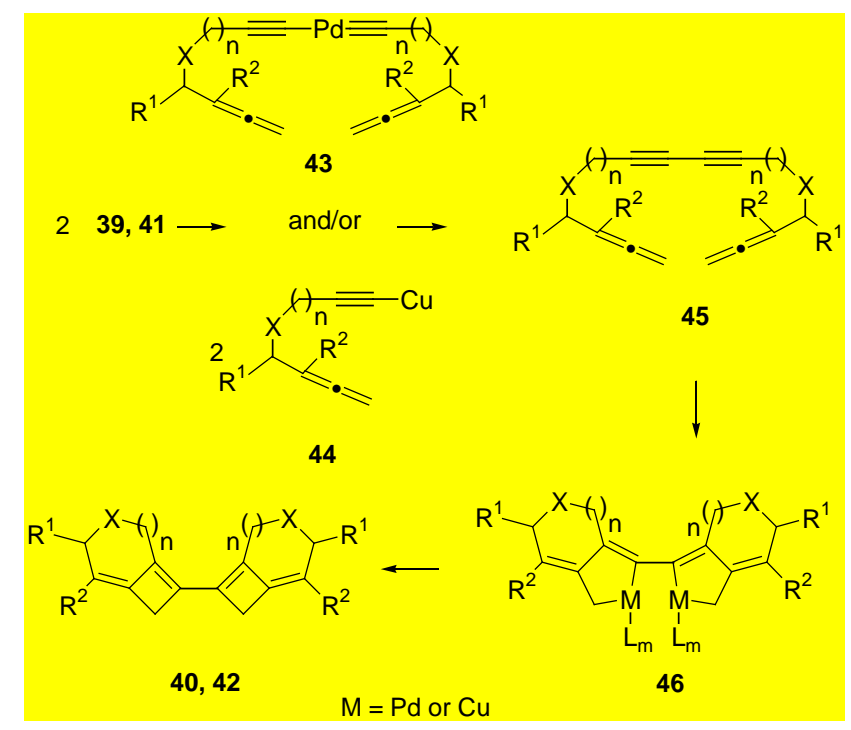

40 Scheme 16 Mechanistic proposal of the palladium-catalyzed or copperpromoted domino alkyne homocoupling/double [2+2] allenyne cycloaddition of ynallenes $\mathbf{3 9}$ and $\mathbf{4 1 .}$

It was proposed that bis(tricycles) $\mathbf{4 2}$ and $\mathbf{4 9}$ were formed from bis( $\beta$-lactam-allenynes) precursors, via formation of tetraradical 45 intermediates. This proposal would include the intermediacy of an exocyclic tetraradical intermediate $\mathbf{5 0}$ through initial double carbon-carbon bond formation, involving the central allene and the proximal alkyne carbon atoms (Scheme 18). Then, the final step must involve a rapid double ring closure of the tetraradical 50 intermediates, before bond rotation can occur. Alternatively, another reaction pathway could be involved, in which one $\beta$ lactam-allenyne cyclizes first and subsequent cyclization of the second allenyne moiety. 


\section{Cite this: DOI: $10.1039 / \mathrm{c0xx00000x}$}

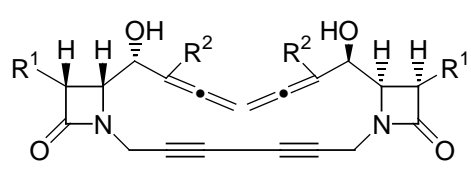

47

$\mathrm{R}^{1}=\mathrm{MeO}, \mathrm{PhO}$

$\mathrm{R}^{2}=\mathrm{Ph}, 4-\mathrm{MeOC}_{6} \mathrm{H}_{4}$

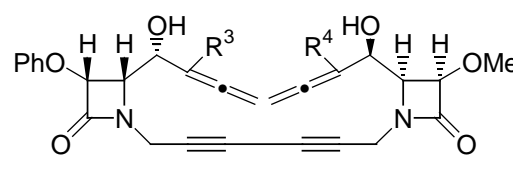

48

$\mathrm{R}^{3}=\mathrm{Ph}, 4-\mathrm{MeOC}_{6} \mathrm{H}_{4}$

$\mathrm{R}^{4}=\mathrm{Ph}, 4-\mathrm{MeOC}_{6} \mathrm{H}_{4}$

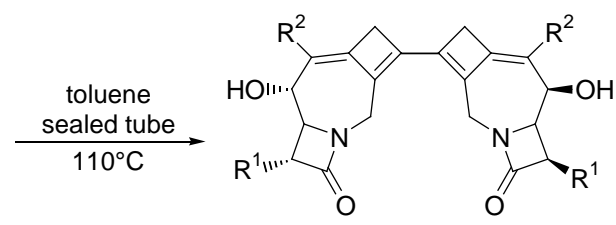

42

65-78\%

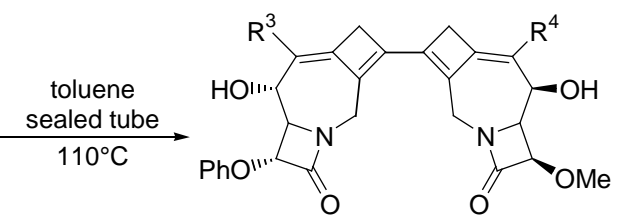

49

Scheme 17 Intramolecular [2+2] cycloaddition of $C_{2}$-symmetric bis( $\beta$-lactam-allenynes) 47 and unsymmetrical allenynes 48 under thermal conditions.

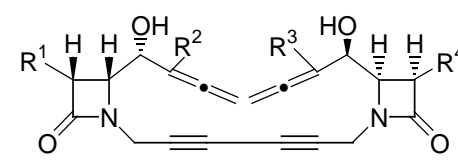

47,48

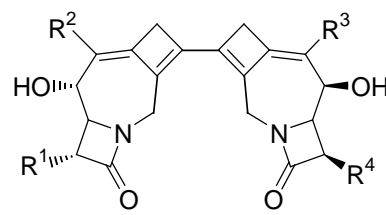

42,49

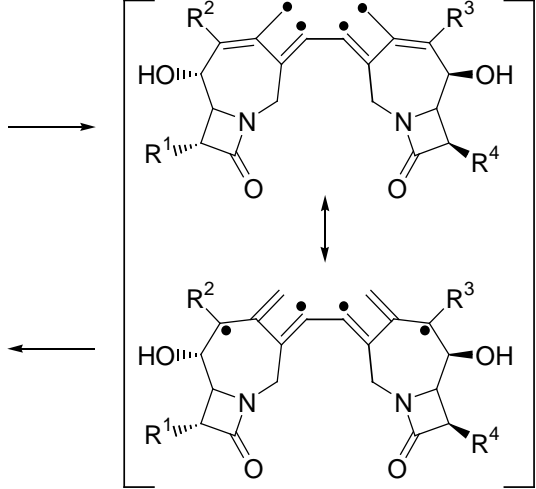

50

5 Scheme 18 Mechanistic explanation of the intramolecular [2+2] cycloaddition. of bis( $\beta$-lactam-allenynes) 47 and 48 via formation of tetraradical intermediates $\mathbf{5 0 .}$

\section{2 [2+2+1] Cycloaddition: The Pauson-Khand Reaction}

\subsubsection{Reactivity Allene-Allene}

10 The Pauson-Khand reaction involves an alkyne $\pi$ bond, an alkene $\pi$ bond and carbon monoxide, affording cyclopentenones via $[2+2+1]$ cycloaddition promoted by different transition metal catalysts, such as Co, $\mathrm{Rh}$, Ir, Mo, $\mathrm{Zr}$ and $\mathrm{Ti}^{22}$ In addition, this reaction has been studied 15 intramolecularly in allenynes instead of enynes for the construction of cyclopentenone-fused bicyclic frameworks. ${ }^{23}$ However, the $[2+2+1]$ cycloaddition of bis(allenes), which requires the participation of the two double bonds, has been studied scarcely and so far there are only two examples in the 20 bibliography. In fact, due to the participation of a metallacycle intermediate in both [2+2] and [2+2+1] cycloaddition mechanisms, usually it has been observed the formation of a mixture of both cycloaddition products. It is important to remark that, for both cycloaddition processes, the external ${ }_{25}$ double bond of each allene moiety is involved in the cyclization reaction, avoiding the possible steric effect of the substituents in the starting material. 
A few years ago, the $\mathrm{Rh}(\mathrm{I})$-catalyzed carbonylative $[2+2+1]$ cycloaddition of bis(allenes) $\mathbf{5 1}$ and $\mathbf{5 2}$ was evaluated. ${ }^{24}$ Treatment of bis(allenes) 51a-c, 52a, and 52b with $[\mathrm{RhCl}(\mathrm{CO}) \mathrm{dppp}]_{2}$ in toluene at $80^{\circ} \mathrm{C}$ under atmosphere of $\mathrm{CO}$ 5 afforded the expected Pauson-Khand products 53a-c, 54a, and 54b (Scheme 19). By contrast, reaction of malonate derivative bis(allene) $51 d$ in the presence of $[\mathrm{RhCl}(\mathrm{CO}) \mathrm{dppp}]_{2}$ furnished a mixture of [2+2] cycloadduct product $\mathbf{5 5}$ as the major product (70\%) along with the Pauson-Khand product 53d (20\%). A 10 satisfactory yield of Pauson-Khand products were observed when bis(allene) 51d was reacted with $\left[\mathrm{RhCl}(\mathrm{CO})_{2}\right]_{2}$ instead of [RhCl(CO)dppp $]_{2}$, yielding Pauson-Khand product 53d in 83\% and [2+2] cycloaddition product 55 in 16\% (Scheme 20).

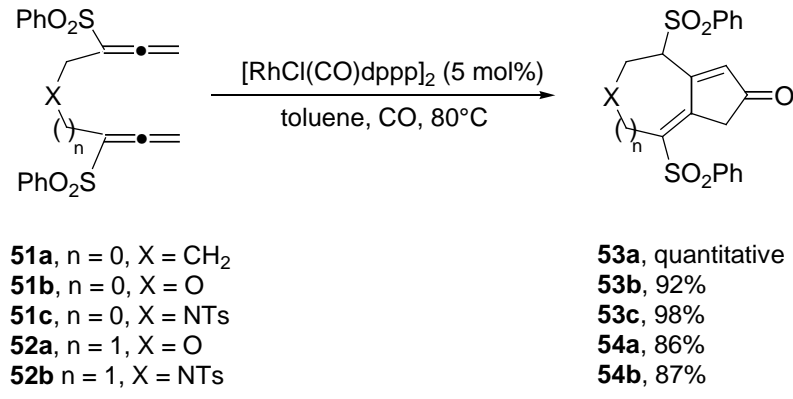

Scheme 19 Synthesis of compounds 53 and 54 via Pauson-Khand reaction of bis(allenes) 51 and 52.

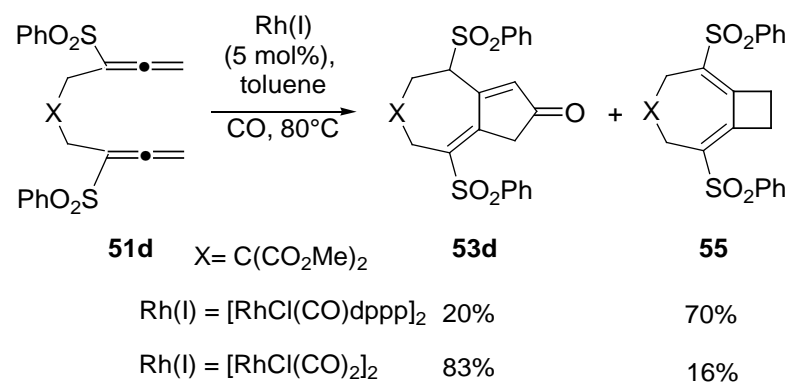

20 Scheme 20 Synthesis of compounds 53d and 55 via competition of Pauson-Khand and [2+2] cycloaddition reactions, respectively.

Formation of both Pauson-Khand and [2+2] cycloaddition products has been explained via cyclometalation between the 25 two external double bonds of the allenyl moieties of bis(allenes) 51 and 52, involving formation of rhodacycle 56 and subsequent isomerization of the initially formed 1,3-diene derivative $\mathbf{5 7}$ to form the $\alpha, \beta$-unsaturated ketones 53a-d, 54a and 54b (Scheme 21). It is presumed that the presence of two 30 bulky phenylsulfonyl groups on both functionalities, should suppress the cyclometalation between two internal double bonds or between a terminal and an internal double bond of two allenyl groups, orienting two terminal double bonds of the allenyl moieties. Compound $\mathbf{5 5}$ would form by reductive 35 elimination of intermediate 56 (Scheme 21).

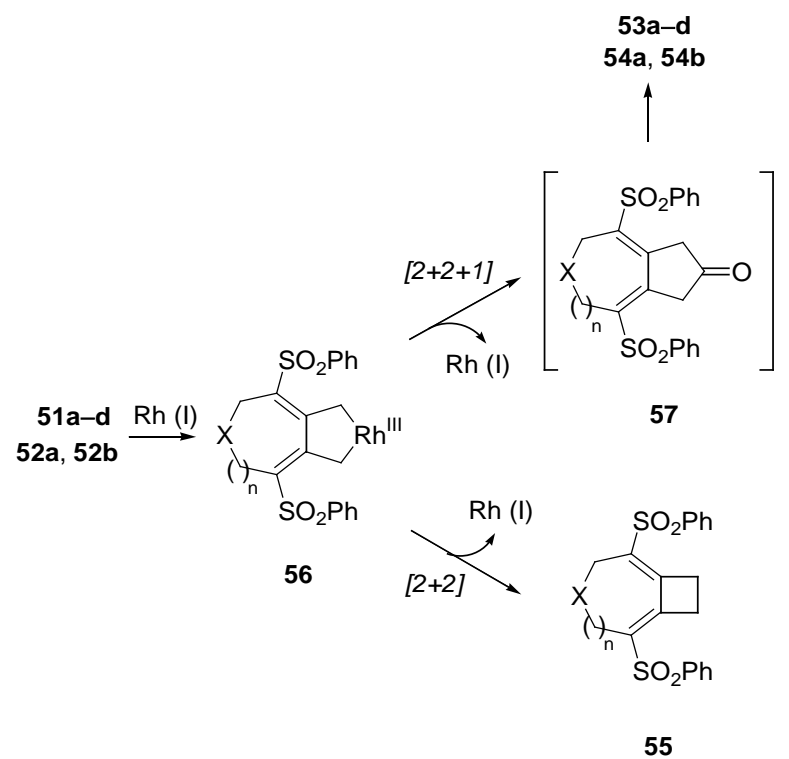

Scheme 21 Possible reaction pathways to explain the formation of $[2+2+1]$ and $[2+2]$ adducts.

In a more recent work, the same authors have successfully 40 applied this methodology for the construction of a 6-8-5 tricyclic ring system from a bis(allene) derivative. ${ }^{25}$ Treatment of allene 58a in the conditions reported previously gave a complex mixture. Fortunatelly, when the reaction was carried out with the bis(allene) derivative $\mathbf{5 8 b}$ possessing phosphonate 45 and sulfonyl groups on the bis(allene) moiety, compound 59b was obtained as single product in 65\% yield (Scheme 22).

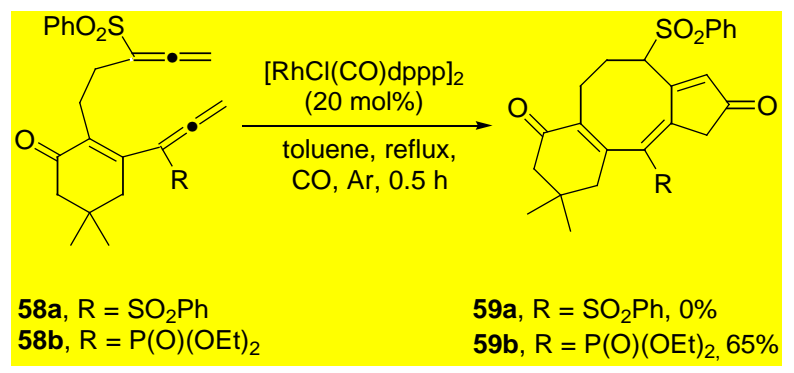

Scheme 22 Synthesis of 6-8-5 tricyclic system 59 via Pauson-Khand reaction of $\mathbf{5 8}$.

\section{2.2.2. Reactivity Allene-Alkyne}

In this context, competition of the $[2+2+1]$ and $[2+2]$ cycloaddition has been observed in bis(allene)-bis(alkyne) compound $\mathbf{6 0} .^{26}$ Thus, reaction of compound $\mathbf{6 0}$ under thermal conditions has afforded compound $\mathbf{6 1}$ in low yield, via [2+2] 55 monocycloaddition of one allene with one alkyne (Scheme 23). However, when bis(allene)-bis(alkyne) $\mathbf{6 0}$ was heated in toluene at $100{ }^{\circ} \mathrm{C}$ in the presence of a slight excess of $\mathrm{Mo}(\mathrm{CO})_{6}$ (2.2 equiv) and DMSO (10 equiv.), [2+2]/[2+2+1] cycloadduct hybrid 62 was obtained as a mixture of diastereoisomers. 60 Interestingly, reaction of bis(allene)-bis(alkyne) $\mathbf{6 0}$ in presence of 10 equiv. of $\mathrm{Mo}(\mathrm{CO})_{6}$ at 53 to $55^{\circ} \mathrm{C}$ afforded compound $\mathbf{6 3}$ via double $[2+2+1]$ cycloaddition allene-alkyne (Scheme 24$)$. 


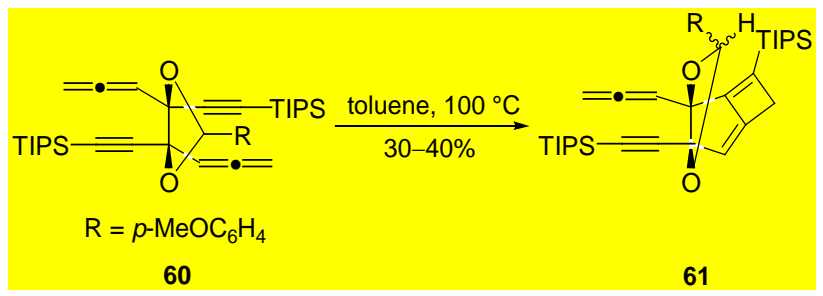

Scheme 23 Reactivity of bis(allenes) 60 under thermal conditions.

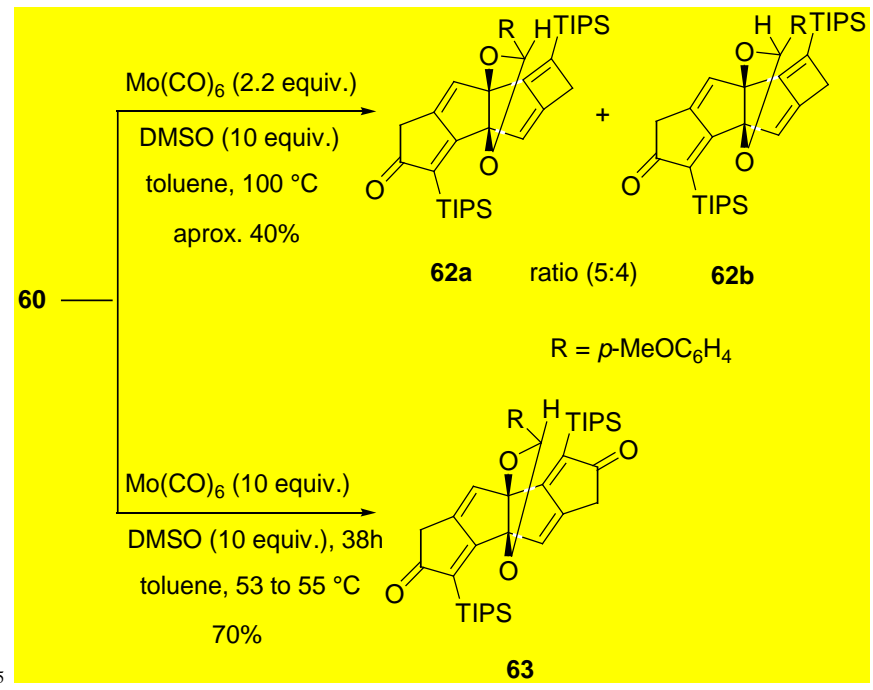

Scheme $24 \mathrm{Mo}(\mathrm{CO})_{6}$-promoted competitive [2+2] and [2+2+1] processes of bis(allene)-bis(alkyne) $\mathbf{6 0}$.

\section{${ }_{10} 2.3$ [4+2] Cycloadditions. Reactivity Allene-Allene}

Bis(allenes) can also participate in Diels-Alder cycloadditions as diene component, affording complex ring structures. First examples reported in the literature were carried out through the reaction of 1,2,4,5-hexatetraene $\mathbf{6 4}$ with different dienophiles, 15 affording the corresponding [4+2] cycloadducts 65 in excellent yields (Scheme 25). ${ }^{27}$

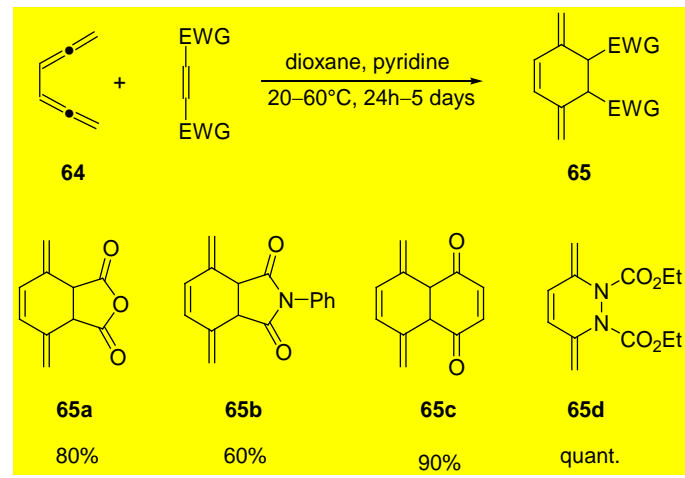

Scheme $25[4+2]$ Cycloaddition of bis(allene) 64 with different 20 dienophiles.

Interestingly, NMR studies of the [4+2] cycloaddition carried out with a mixture of syn- and anti-bis(allenes) $\mathbf{6 6}$ in presence of $\mathrm{N}$-phenylmaleimide have shown that the reaction is stereospecific. Thus, [4+2] cycloadduct 67a was detected after 25 22h, leaving anti-66 unaltered (Scheme 26). ${ }^{28}$ However, bis(allene) anti-66 reacted with $\mathrm{N}$-phenylmaleimide after 5 days, affording cycloadduct $\mathbf{6 7} \mathbf{b}$. This behavour can be explained taking into account that the dienophile approaches by the less sterically hindered face of the bis(allene).

Scheme 26 Stereospecific [4+2] cycloaddition of bis(allenes) 66 with $N$-phenylmaleimide.

On the other hand, once again, taking advantage of the [2,3]35 sigmatropic rearrangement of bis(propargylic alcohol) derivatives to form the corresponding bis(allenes), it has been described the synthesis of the steroid skeleton via a sigmatropic rearrangement/6$\pi$-electrocyclic reaction/intramolecular [4+2] cycloaddition sequence. $^{29}$ Thus, treatment of ene40 bis(progargylic alcohol) $\mathbf{6 8}$ with benzenesulfenyl chloride effected the consecutive four-step conversion in one operation. It involves the intermediacy of bis(allene) 69, which is converted in the diene component of the cycloaddition process through $6 \pi$-electrocyclization. Finally, providing the steroid 45 framework, namely compound $\mathbf{7 0}$, in $32 \%$ overall yield (Scheme 27).

Recently, it has been described the synthesis of bis(allene $\beta$ lactams) by reaction of 4-acetoxy-2-azetidinones with 50 organoindium reagents followed by intermolecular Diels-Alder reaction with a variety of dienophiles. ${ }^{30}$ Synthesis of $\beta$-lactam bis(allenes) has been achieved by reaction of 4-acetoxy-2azetidinone $\mathbf{7 1}$ with organoindium reagent generated in situ from indium and 1,6-dibromo-2,4-hexadiyne in the presence of ${ }_{55} \mathrm{LiCl}$ as additive, producing compound 72 in good yield (Scheme 28). Next, the authors studied the Diels-Alder reaction of bis(allenes) 72 with various dienophiles affording highly functionalized $\beta$-lactams $\mathbf{7 3}$ in good yields. 
Scheme 27 Synthesis of the steroid framework 70 via intramolecular allenic [4+2] cycloaddition.

\section{Cyclization reactions of bis(allenes)}

Transition-metal-catalyzed reactions of polyunsaturated compounds have captivated chemists of all areas. This is mainly due to the huge synthetic potential for the preparation of a variety of carbo- and heterocyclic structures under mild 10 conditions with high yields and stereoselectivity. ${ }^{31}$ In particular, metal-catalyzed cyclization of allenes has led to many synthetically useful transformations. ${ }^{1}$ In the following section we discuss the examples reported in the bibliography concerning the reactivity of bis(allenes) in the presence of 15 different metal catalytic systems. This section has been divided in two subsections: a) Formation of new $\mathrm{C}-\mathrm{C}$ bonds (carbocyclizations), and b) Formation of new $\mathrm{C}-\mathrm{O}$ bonds (heterocyclizations).

\subsection{Formation of new $\mathrm{C}-\mathrm{C}$ bonds: Carbocyclizations}

\section{3.1.1 Reactivity Allene-Allene}

The presence of four $\pi$ components in the molecule of a bis(allene) can produce three different types of cyclometalations in the presence of a transition metal catalyst (Scheme 29): a) metal coordinative cyclization between both 25 terminal double bonds to form intermediate I, b) metal coordinative cyclization between both internal double bonds to form intermediate II, and c) metal coordinative cyclization between an internal double bond and a terminal double bond to form intermediate III. Formation of each intermediate can be 30 controlled by the metal catalyst, the reaction conditions and the structure of both starting material and the final compound.

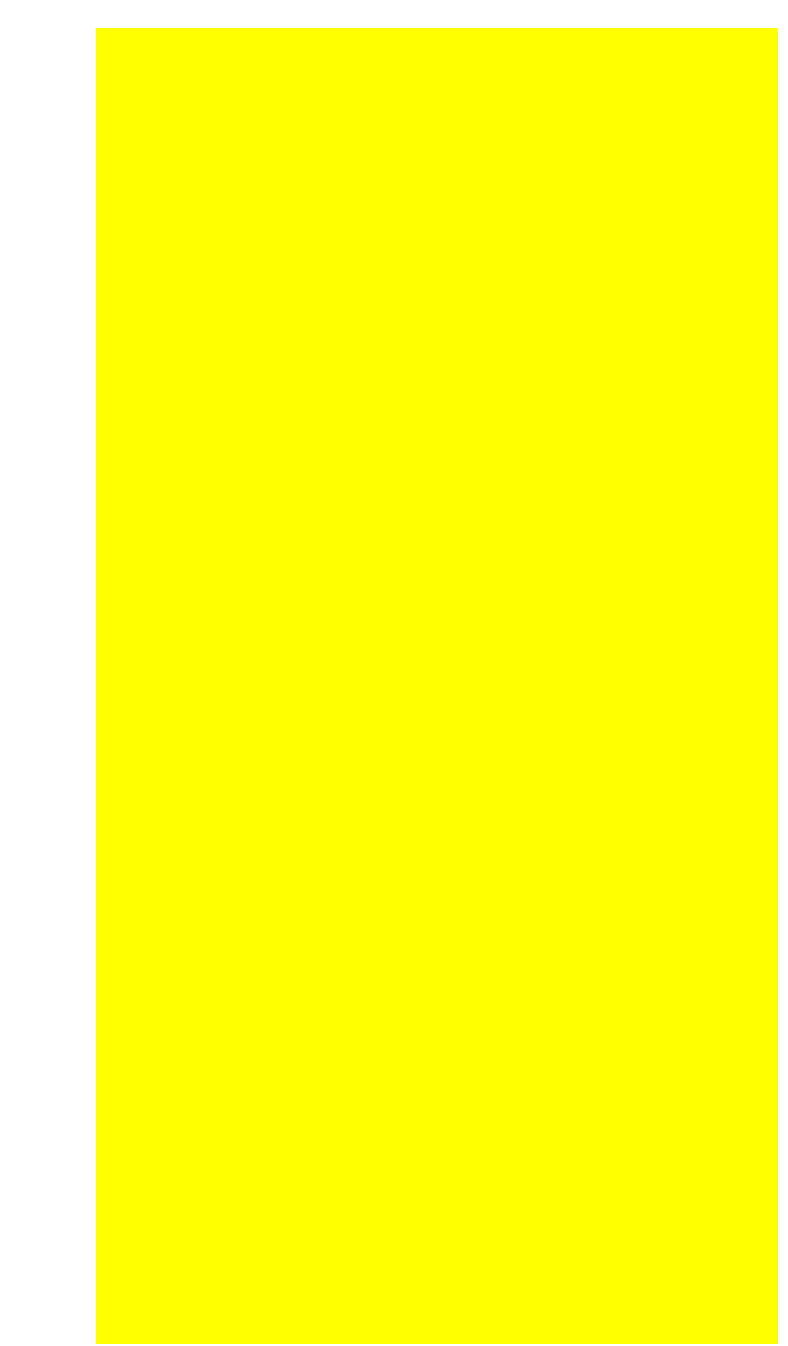

Scheme 28 Synthesis of cyclohexenyl $\beta$-lactams 73 via [4+2] 35 cycloadittion of bis(allenes) 72 with different dienophiles.

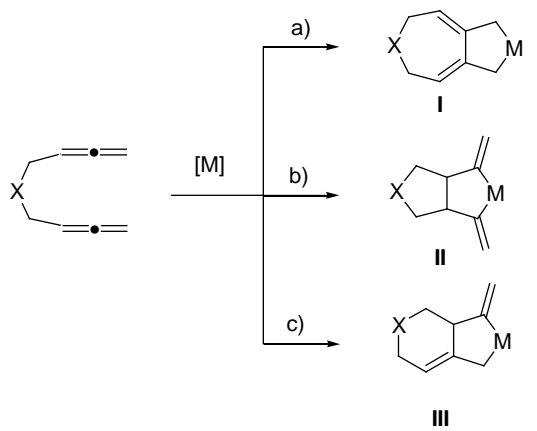

Scheme 29 Possible types of cyclometalations of a bis(allene) in the presence of a transition metal catalyst.

The reactivity of 1,5-bis(allenes) in presence of catalytic 40 amounts of $\left[\mathrm{RhCl}(\mathrm{CO})_{2}\right]_{2}$ has been studied. ${ }^{32}$ Reaction of bis(allenes) 74 in presence of $2 \mathrm{~mol} \%$ of $\left[\mathrm{RhCl}(\mathrm{CO})_{2}\right]_{2}$ in acetonitrile as solvent afforded seven-membered crossconjugated trienes 75 (Scheme 30). Apparently, the use of acetonitrile as solvent is crucial. Probably, the nitrile group 45 may coordinate the catalytically active rhodium species to suppress the formation of oligomeric byproducts. The scope of the reaction has been studied using different alkyl substituents 
and tethers. In addition, to make the most of this methodology, the diene unit of the cross-conjugated triene has been reacted with different dienophiles to afford complex polycyclic compounds (Scheme 31). ${ }^{33}$ For example, when compound 75a 5 was treated with $\mathrm{N}$-ethylmaleimide under catalysis of $[\mathrm{RhCl}(\mathrm{cod})]_{2} /$ dppe/AgOTf, tricyclic compound $\mathbf{7 6 a}$ was obtained instead the expected [4+2] adduct 77. Formation of compound 76a could be formed via in situ generated triene $\mathbf{7 8 .}$
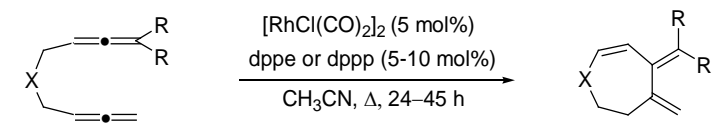

$$
\begin{array}{r}
\text { 74a, 74b } \mathrm{R}, \mathrm{R}=\mathrm{Me}, \mathrm{Me} \\
\mathrm{X}=\mathrm{C}\left(\mathrm{CO}_{2} \mathrm{Me}\right)_{2} \text {, NTs } \\
\text { 74c, 74d } \mathrm{R}, \mathrm{R}=-\left(\mathrm{CH}_{2}\right)_{5}- \\
X=\mathrm{C}\left(\mathrm{CO}_{2} \mathrm{Me}\right)_{2} \text {, NTs }
\end{array}
$$

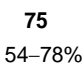

Scheme 30 Rh(I)-catalyzed cyclization of bis(allenes) 74 .<smiles>CCN1C(=O)C=CC1=O</smiles><smiles>C=C1CCC(C(C)=O)(C(C)=O)C=CC1=C(C)C</smiles>

$[\mathrm{RhCl}(\mathrm{cod})]_{2}(2 \mathrm{~mol} \%)$

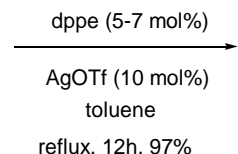

$80^{\circ} \mathrm{C}, 42 \mathrm{~h}, 89 \%$
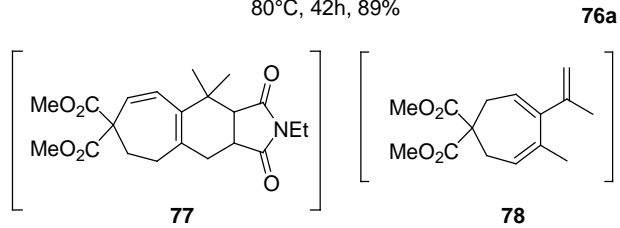

Scheme 31 Synthesis of tricyclic compound $\mathbf{7 6 a}$ via [4+2] cycloaddition of compound 75a with $N$-ethylmaleimide.

15

A possible mechanism for the formation of compounds $\mathbf{7 5}$ has been proposed (Scheme 32). First, bis(allene) 74 undergoes cycloisomerization to afford seven-membered bisallylic rhodium intermediate $\mathbf{7 9}$, which would undergo highly 20 regioselective $\beta-\mathrm{H}$ elimination affording intermediate $\mathbf{8 0}$. Subsequent reductive elimination would afford compounds $\mathbf{7 5}$ with regeneration of the rhodium catalyst.

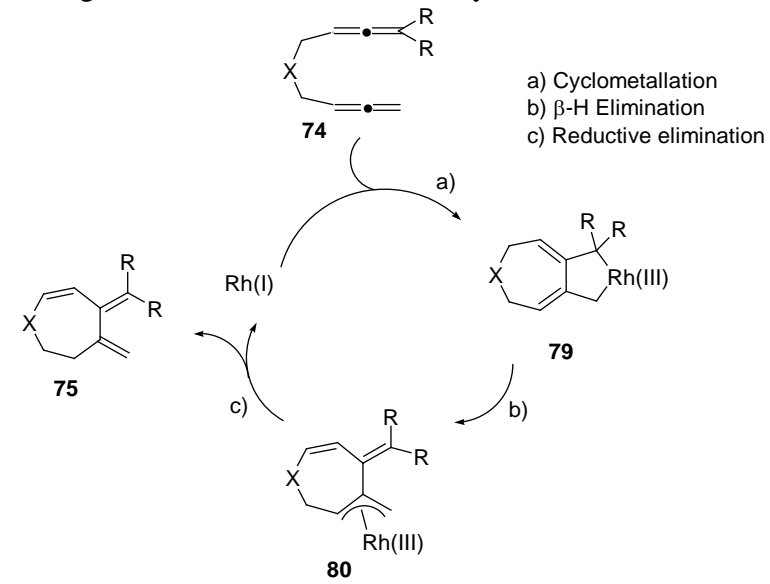

Scheme 32 Mechanistic proposal to explain the formation of 25 compounds 75 from bis(allenes) 74.
Fascinated by these results, the same research group continued studying the reactivity of 1,5-bis(allenes). Interestingly, changing the substitution of the bis(allene), the metal catalyst 30 and the reaction conditions, a different reactivity has been studied. In the event, researchers observed that the rhodiumcatalyzed reaction of bis(allene) 1a lacking substitution at the terminal position of both allene moieties, afforded heterosteroid compound $\mathbf{8 1}$ in moderate to good yields (Scheme 33). ${ }^{34}$ The 35 scope of the reaction was studied using other bis(allenes), 1 f and $\mathbf{1 g}$, affording compounds $\mathbf{8 1 a - c}$ in moderate to good yields.

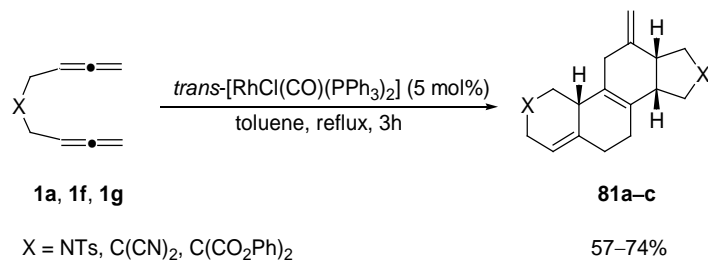

Scheme 33 Synthesis of heterosteroid 81 via rhodium-catalyzed 40 reaction of bis(allenes) 1.

Compounds $\mathbf{8 1}$ have been obtained by reaction of two molecules of the starting bis(allene).The reaction mechanism would involve cyclometalation between both internal double bonds of the bis(allene) 1 to give intermediate 82, which would 45 undergo carbometalation with one of the two allene moieties in 1 to afford 83 (Path A, Scheme 34). Subsequent reductive elimination of intermediate $\mathbf{8 3}$ would afford $\mathbf{8 4}$, which could then undergo a Diels-Alder reaction to form the 18,19norsteroid 81. An alternative pathway would involve the 50 formation of intermediate $\mathbf{8 5}$, formed by cyclometalation between one internal double bond of one allene and the external double bond of the other allene moiety of bis(allene). An analogous route would be proposed for the formation of $\mathbf{8 1}$ via intermediates 85-87 (Path B, Scheme 34).

55 In order to explore the dimerization of bis(allenes) $\mathbf{1}$, it has been studied the $\mathrm{Rh}(\mathrm{I})$-catalyzed cyclization between two different 1,5-bis(allenes). ${ }^{35}$ In the event, four possible isomers could be obtained. The cross-cyclization of two different tethered bis(allenes) $\mathbf{1}$ was tested using the conditions 60 described previously. Thus, reaction of both bis(allenes) in presence of trans-[RhCl$\left.(\mathrm{CO})\left(\mathrm{PPh}_{3}\right)_{2}\right]$ in toluene at reflux temperature afforded a mixture of steroid-scaffold products $\mathbf{8 1}$ and 88-90 (Scheme 35). Notably, only two products were obtained when the heteroatom was oxygen. Probably, the large 65 angle of the $\mathrm{C}-\mathrm{O}-\mathrm{C}$ bond in bis(allene) $\mathbf{1 h}$, makes cyclometalation of its two allene moieties more difficult. This hypothesis was confirmed when the treatment of bis(allene) $\mathbf{1 h}$ $(\mathrm{X}=\mathrm{O})$ with $\mathrm{Rh}(\mathrm{I})$ did not afford the dimerization compound 81. The reaction showed good stereoselectivity in all cases, 70 thus, although three new stereogenic centers are form in the reaction, only one diastereomer with cis conjunction of the rings was formed. 


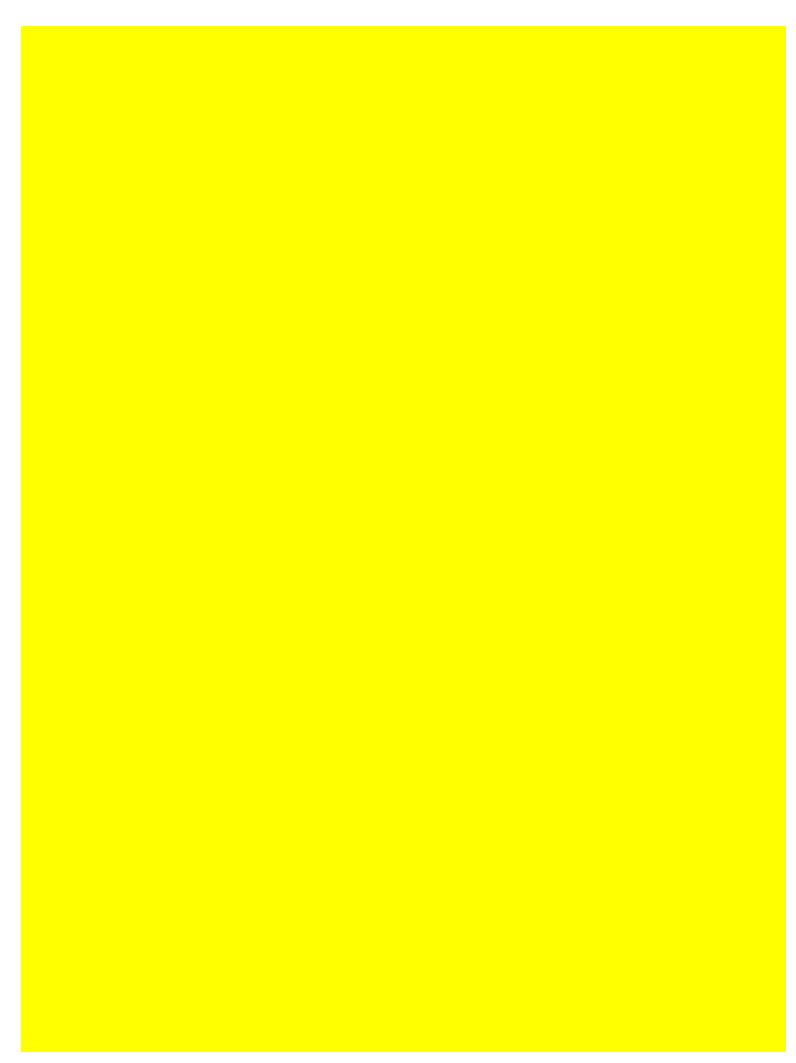

Scheme 34 Mechanistic proposal for the rhodium-catalyzed synthesis of steroid skeletons from 1,5-bis(allenes) 1.

5 Interestingly, tricyclic product $\mathbf{9 1}$ was formed along with tetracycle 81d when bis(allene) 1i, $\mathrm{X}=\mathrm{C}\left(\mathrm{CO}_{2} \mathrm{Me}\right)_{2}$, and bis(2,3-butadienyl)sulfide $\mathbf{1} \mathbf{j}$ were used in the reaction (Scheme 36). The mechanistic explanation for the formation of compound $\mathbf{9 1}$ is proposed in Scheme 37. First, cyclometalation 10 of the bis(allene) $\mathbf{1 i}$ with $\mathrm{Rh}(\mathrm{I})$ catalyst affords the intermediate 92. The rhodium atom in this intermediate coordinates with the sulfur atom in bis(allene) $\mathbf{1} \mathbf{j}$, which leads to the formation of vinylic rhodium intermediate $\mathbf{9 3}$ through regioselective carbometalation. The subsequent intramolecular

15 carbometalation of $\mathbf{9 3}$ with the terminal $\mathrm{C}=\mathrm{C}$ double bond of the allene moiety forms intermediates 94 or $\mathbf{9 5}$. Reductive elimination of $\mathbf{9 4}$ or $\mathbf{9 5}$ affords the tricyclic product $\mathbf{9 1}$ and regenerates the $\mathrm{Rh}(\mathrm{I})$ catalyst. Notably, the formation of product 96, which would involve cyclometalation between both 20 internal double bonds of the bis(allenes) was not observed in the reaction of $\mathbf{1} \mathbf{i}$ and $\mathbf{1} \mathbf{j}$.

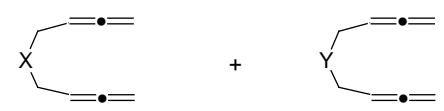

$$
\begin{array}{ll}
\text { 1a, } X=\mathrm{NTs} & \mathbf{1 b}, \mathrm{Y}=\mathrm{C}\left(\mathrm{SO}_{2} \mathrm{Ph}\right)_{2} \\
\text { 1h, } \mathrm{X}=\mathrm{O} & \mathbf{1 f}, \mathrm{Y}=\mathrm{C}(\mathrm{CN})_{2} \\
& \mathbf{1 i}, \mathrm{Y}=\mathrm{C}\left(\mathrm{CO}_{2} \mathrm{Me}\right)_{2}
\end{array}
$$

trans-[RhCl(CO) $\left.\left(\mathrm{PPh}_{3}\right)_{2}\right](5 \mathrm{~mol} \%)$

toluene, reflux, $3 \mathrm{~h}$

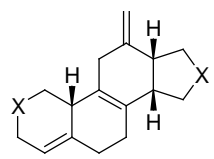

81

$\mathrm{X}=\mathrm{NTs}, \mathrm{Y}=\mathrm{C}\left(\mathrm{CO}_{2} \mathrm{Me}\right)_{2} \quad 20 \%$

$\mathrm{X}=\mathrm{NTS}, \mathrm{Y}=\mathrm{C}(\mathrm{CN})_{2} \quad 18 \%$

$\mathrm{X}=\mathrm{O}, \mathrm{Y}=\mathrm{C}\left(\mathrm{SO}_{2} \mathrm{Ph}\right)_{2}$

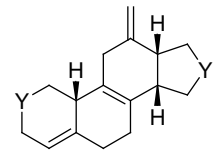

88

$30 \%$

$33 \%$

$38 \%$

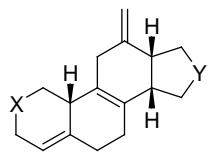

89

$12 \%$

$13 \%$

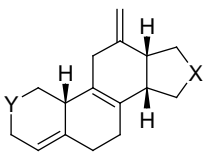

90

$9 \%$

$9 \%$

$7 \%$

Scheme 35 Synthesis of heterosteroids $\mathbf{8 1}, \mathbf{8 8 - 9 0}$ via rhodium-catalyzed reactions of bis(allenes) $\mathbf{1}$.

Scheme 36 Synthesis of compounds $\mathbf{8 1 d}$ and $\mathbf{9 1}$ via rhodium-catalyzed reaction of bis(allenes) $\mathbf{1 i}$ and $\mathbf{1 j}$. 


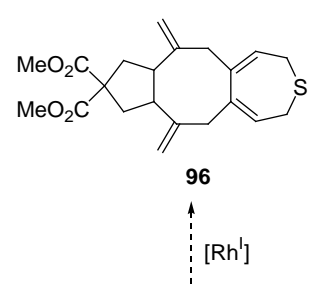

a) Cyclometalation

b) Carbometalation

c) Reductive Elimination

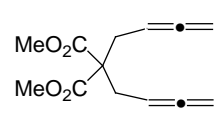

$1 \mathbf{i}$

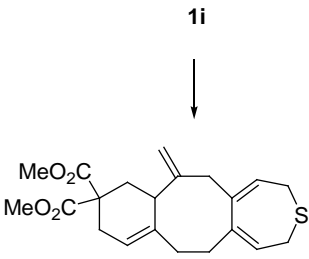

91

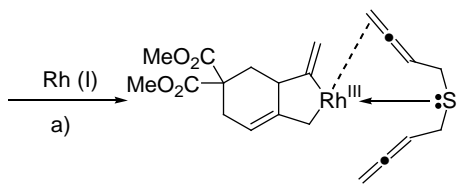

92

1j

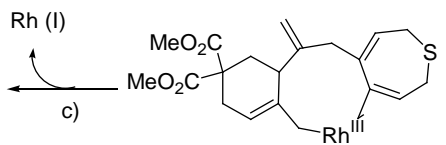

95

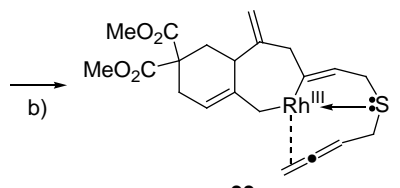

93

b)

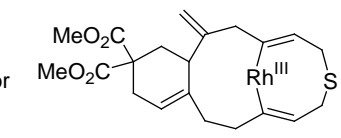

94

Scheme 37 Synthesis of compound $\mathbf{9 1}$ via intermolecular rhodium-catalyzed reaction of bis(allenes) $\mathbf{1 i}$ and $\mathbf{1 j}$.

5 Latter on, the synthesis of bicyclo[4.4.0] decene skeletons via rhodium catalyzed cyclization of 1,5-bis(allenes) in the presence of monoallenes has been described. ${ }^{36}$ If the reaction conditions, such as dilution an slow addition of one of the reagents can be controlled, bis(allene) $\mathbf{1 b}$ can react with allenes ${ }_{10} \mathbf{9 7}$, without formation of the dimerization product previously described. Thus, reaction of bis(allene) $\mathbf{1 b}, \mathrm{X}=\mathrm{C}\left(\mathrm{SO}_{2} \mathrm{Ph}\right)_{2}$, and allenes 97 using trans- $\mathrm{RhCl}(\mathrm{CO})\left(\mathrm{PPh}_{3}\right)_{2}$ as catalyst afforded bicyclo[4.4.0]decene product $\mathbf{9 8}$ in moderate yields. Subsequent Diels-Alder reaction of the conjugated exocyclic 15 diene of $\mathbf{9 8}$ in the presence of maleimides provided tetracyclic skeleton 99 with high diastereoselectivity and yield (Scheme 38).

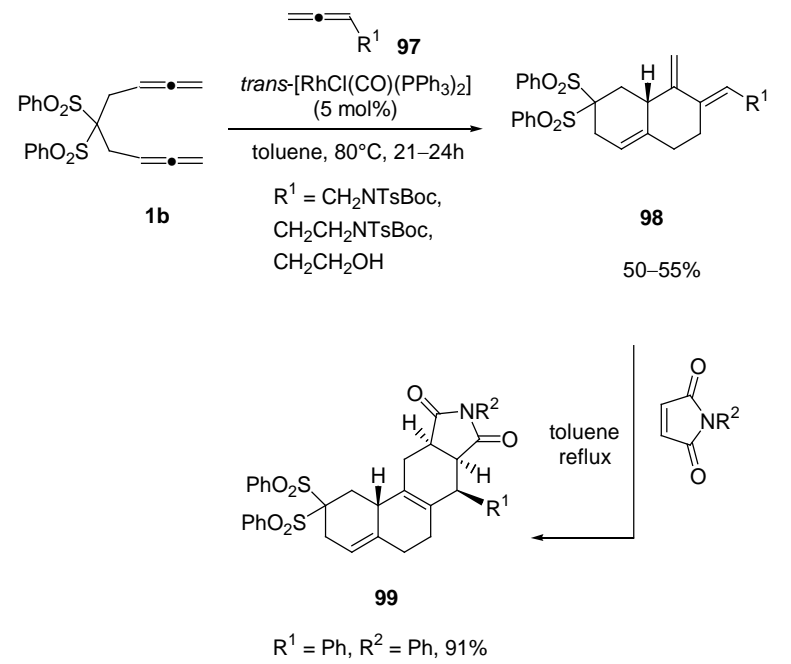

Scheme 38 Synthesis of compounds 98 via intermolecular rhodium20 catalyzed reaction between bis(allene) $\mathbf{1 b}$ with allenes $\mathbf{9 7}$ and subsequent Diels Alder to form compounds $\mathbf{9 9}$.

More recently, during the studies on carbonylative [2+2+1] cycloaddition of bis(sulfonylallenes), it has been reported its 25 rhodium(I)-catalyzed cycloisomerization. ${ }^{24 \mathrm{~b}}$ Thus, reaction of bis(sulfonylallene) 100 using $[\mathrm{RhCl}(\mathrm{CO}) \mathrm{dppp})]_{2}$ (10 mol\%) as catalyst under $\mathrm{CO}$ atmosphere in toluene at reflux, afforded a mixture of cycloisomerization product 101a (69\%) and [2+2+1] cycloaddition product 102 (5\%) (Scheme 39). Obviously, CO 30 was not involved in the cycloisomerization. For this reason, when the reaction was performed with bis(allene) 101a in absence of CO, nine-membered cycle 101a was obtained as sole product in $96 \%$ yield. Other carbon- and nitrogen- analogs were obtained in reasonable yields, although in one case, for 35 bis(allene) 100d, a small amount of [2+2] cycloaddition product 103 was isolated. The reaction of bis(allenes) 52c and 52d under the same reaction conditions afforded cyclooctene derivatives 104 in high yields along with a small yield of [2+2+1] cycloaddition by-products 105 (Scheme 39).

40 Formation of compounds 101 and 104 from bis(allenes) 52c, 52d and 100a-e, could be explained through formation of rhodacycle intermediate 106, formed via metal coordinative cyclization between both terminal double bonds followed by thermal [1,5]-H shift (Scheme 40). The resulting intermediate ${ }_{45} 95$ would afford compounds 101 and 104 via a reductive elimination step. 

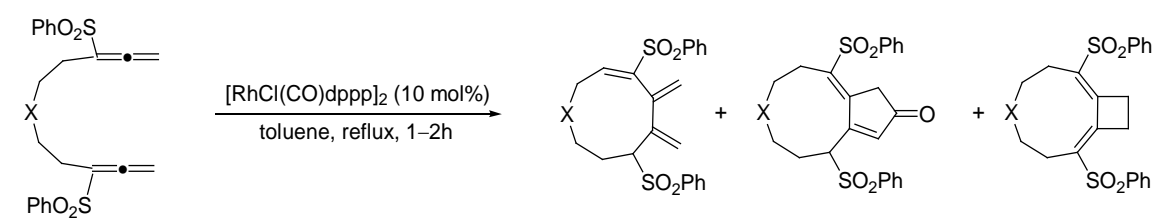

$\begin{array}{lcc}100 \mathrm{a}, \mathrm{X}=\mathrm{C}\left(\mathrm{CO}_{2} \mathrm{Me}\right)_{2}, & \mathrm{CO} \text { atm } & 101 \mathrm{a}(69 \%) \\ 100 \mathrm{a}, \mathrm{X}=\mathrm{C}\left(\mathrm{CO}_{2} \mathrm{Me}\right)_{2} & - & 101 \mathrm{~b}(96 \%) \\ 100 \mathrm{~b}, \mathrm{X}=\mathrm{CH}_{2} & - & 101 \mathrm{c}(71 \%) \\ 100 \mathrm{c}, \mathrm{X}=\mathrm{NNs} & - & 101 \mathrm{~d}(70 \%) \\ 100 \mathrm{~d}, \mathrm{X}=\mathrm{NTs} & - & 101 \mathrm{e}(67 \%)\end{array}$

102
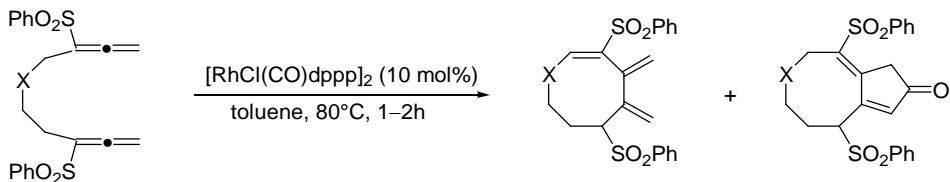

52c, $X=\mathrm{CH}_{2}$

52d, $\mathrm{X}=\mathrm{C}\left(\mathrm{CO}_{2} \mathrm{Me}\right)_{2}$

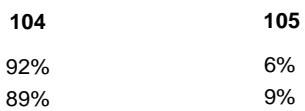

Scheme 39 Rhodium-catalyzed cycloisomerization of compounds 52c and 52d.

Scheme 40 Mechanistic explanation for the synthesis of compounds 100 and 104 from bis(allenes) 52c, 52d and 100.

On the other hand, the cyclization reaction of 2,3-allenoic acids 10 in the presence of simple alkyl- or aryl-substituted allenes has been studied. ${ }^{37}$ In fact, reaction of allenoic acids 108a with allenes 109 in the presence of $\mathrm{Pd}(\mathrm{OAc})_{2}$ (2 mol\%), $\mathrm{LiBr} \cdot \mathrm{H}_{2} \mathrm{O}$ and benzoquinone in acetic acid at $60^{\circ} \mathrm{C}$ afforded compounds 110 in moderate to good yields. A plausible mechanism 15 involves the cyclic oxypalladation of 2,3-allenoic acid 108a with $\mathrm{Pd}(\mathrm{II})$ to the furanoyl palladium intermediate 111, which could be trapped by the simple allene to form a $\pi$-allylic intermediate 112 (Scheme 41). This intermediate could be attacked by a bromide anion to yield compounds $\mathbf{1 1 0}$. The in 20 situ formed $\operatorname{Pd}(0)$ was efficiently converted to the catalytically active Pd(II) species by benzoquinone in acetic acid.

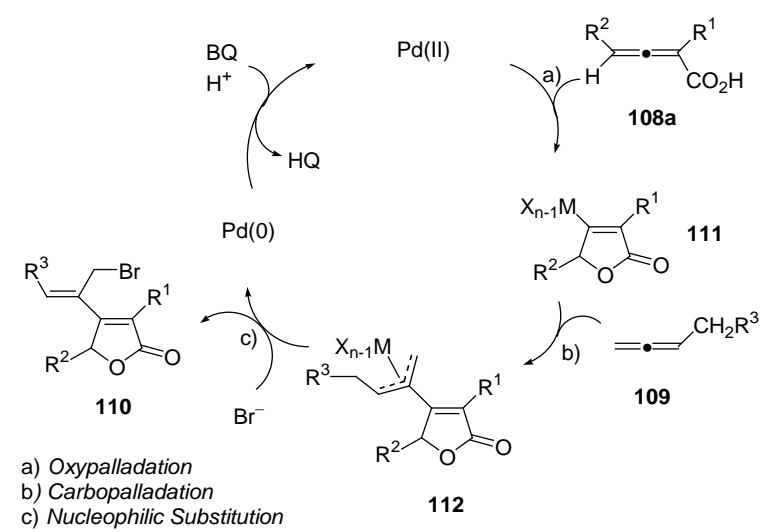

Scheme 41 Synthesis of furans 110 via cyclization reaction of 2,325 allenoic acids with substituted allenes.

Based on the above precedent, the authors reasoned that the cyclization of 2,3-allenoic acids in the presence of 1,5bis(allenes) may involve further cyclization to form compounds 30113 (Scheme 42). ${ }^{38}$ However, when bis(allene) 1a was treated 
with 2,3-allenoic acid $\mathbf{1 0 8 b}$ using the above reaction conditions, an unidentified mixture was obtained instead of the expected compound 113. Interestingly, when the reaction between substrates $\mathbf{1 a}$ and $\mathbf{1 0 8 b}$ was catalyzed by ${ }_{5}\left[\mathrm{PdCl}_{2}(\mathrm{PhCN})_{2}\right]$ in DMSO, two tricyclic products cis-114a and 115a were obtained without incorporation of the bromide anion (Scheme 43). In order to improve the selectivity of cis-114/115 different conditions were tested. Taking into account, that $\mathrm{LiBr} \cdot \mathrm{H}_{2} \mathrm{O}$ is not involved in the formation of both compounds, 10 it was suppressed. Then, the optimum reaction conditions were the use of $\left[\mathrm{PdCl}_{2}(\mathrm{PhCN})_{2}\right] \quad(5 \mathrm{~mol} \%)$ and 1,4bis(diphenylphosphino)butane (5 mol\%) as ligand. Thus, sandwich-type compounds $\mathbf{1 1 4}$ were obtained with excellent stereoselectivity and yields (Scheme 43).

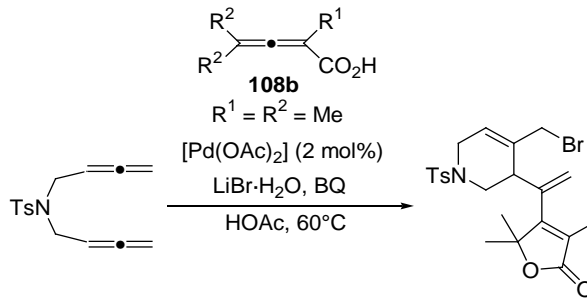

$1 \mathrm{a}$

113

Scheme 42 Failed reaction of bis(allene) $\mathbf{1 a}$ and 2,3-allenoic acid $\mathbf{1 0 8 b}$

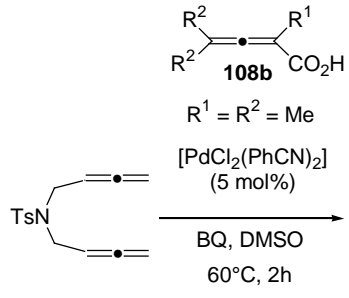

$1 \mathrm{a}$

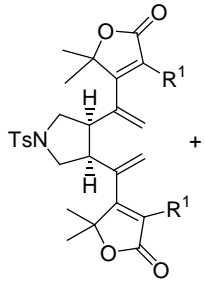

cis-114a

$32 \%$

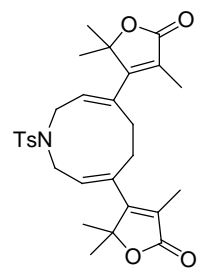

$115 a$

$10 \%$

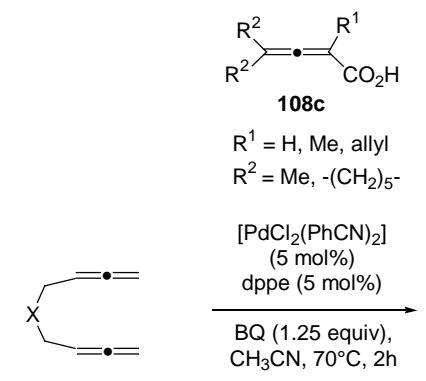

$1 \mathrm{a}, 1 \mathrm{~h}, 1 \mathrm{k}$

$\mathrm{X}=\mathrm{NTS}, \mathrm{O}, \mathrm{CH}_{2}$

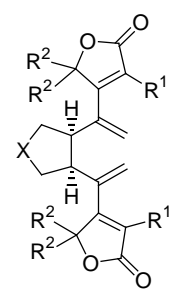

cis-114

$52-81 \%$

Scheme 43 Synthesis of compounds 114 and 115 by reaction of 20 bis(allenes) $\mathbf{1}$ and 2,3-allenoic acids $\mathbf{1 0 8}$.

Interestingly, when the enantioenriched (S)-2,3-allenoic acid 108d was treated with bis(allene) 11 under the optimal conditions, the optically active product $(S, R, S, S)-\mathbf{1 1 4 b}$ was 25 isolated. This example showed the excellent chirality transfer from the axial chirality of the optically active allenoic acid to the product (Scheme 44).

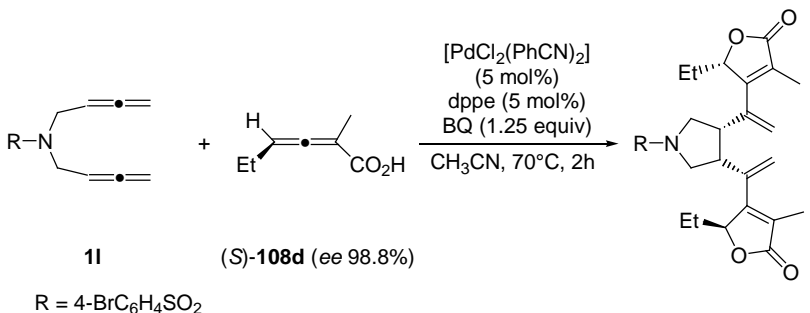

$(\mathrm{S}, R, S, S)-114 b$ $63 \%$

Scheme 44 Enantioenriched synthesis of compound 114b from bis(allene) $\mathbf{1 l}$ and 2,3-allenoic acid (S)-108d.

A possible mechanism for this transformation would start with 35 the stereoselective cyclic anti-oxypalladation of $(S)$-108d to form intermediate $\mathbf{1 1 1}$ with a center of chirality (Scheme 45). Subsequent carbopalladation of one allene moiety in bis(allene) 1 with 111 would form the $\pi$-allylic intermediate 116a or $\mathbf{1 1 6 b}$. Taking into account the steric interaction between the 40 pseudoaxial proton and the $2(5 \mathrm{H})$-furanonyl vinyl group in $\mathbf{1 1 6 b}$, the reaction proceeds via the intermediate 116a to generate cis-117. A second molecule of 2,3-allenoic acid (S)108d would undergo sequential coordination and antioxypalladation with the vinyl palladium cis-117 to generate cis-

45 118, which upon reductive elimination would release the final tricyclic product $(S, R, S, S)-\mathbf{1 1 4 b}$ and $\mathrm{Pd}(0)$. The Pd (II) catalyst would be finally regenerated by the reaction of $\operatorname{Pd}(0)$ with $B Q$ and $\mathrm{H}^{+}$.

Multicomponent reactions are very powerful synthetic 50 processes, which allow achieving both complexity and diversity in a single and simple experimental step with high efficiency and atom economy. ${ }^{39}$ The applicability of the multicomponent reactions has been widely demonstrated in the synthesis of natural products, ${ }^{40}$ and medicinal chemistry. ${ }^{41}$

55 It has been reported that palladium-catalyzed coupling reaction of propargylic carbonates with boronic acids or organozinc reagents afford alkynes or allenes depending on the steric hindrance of the starting materials. ${ }^{42}$ Taking into account this methodology, recently, Ma and col. have reported the 60 palladium (0)-catalyzed three component coupling reaction of 1,5-bis(allenes), propargylic carbonates and organoboronic acids. ${ }^{43}$ It is important to note that progargyl carbonates act as 1,2-allenyl intermediates in the process, involving three allene functionalities in the reaction, showing the great complexity of 65 the process. Interestingly, multicomponent reactions between bis(allenes) 1a, 1b and 1m, propargyl carbonates 119 and phenyl boronic acids 120 catalyzed by $\left[\mathrm{Pd}(\mathrm{dba})_{2}\right]$ (5 mol\%), afforded bicyclic products $\mathbf{1 2 1}$ as single cis-diastereomers (Scheme 46). Interestingly, compounds 121 were not obtained 
in the absence of $\mathrm{Na}_{2} \mathrm{CO}_{3}$, while the optimum catalyst was the use of $\left[\mathrm{Pd}(\mathrm{dba})_{2}\right]$ in the presence of a phosphine. The reaction was very general for bis(allenes) $\mathbf{1}$ and propargylic carbonates 119. Phenyl boronic acids 120 with electron-withdrawing and 5 electron-donating substituents were all suitable substrates. A plausible mechanism for the formation of compounds $\mathbf{1 2 1}$ is shown in Scheme 47. The catalytic cyclization starts by the oxidative addition of palladium(0) with the propargyl carbonate 119, generating the 1,2-allenyl palladium species 122. 10 Subsequent carbopalladation of 1,5-bisallene $\mathbf{1}$ with $\mathbf{1 2 2}$ would form the $\pi$-allylic species syn-123, which intramolecularly undergoes carbometalation to afford the vinyl palladium species cis-124 highly stereoselectively. The cisstereoselectivity has been explained by the fact that $\pi$-allylic 15 intermediate $\mathbf{1 2 5}$ would easily isomerizes to the more stable 126 to avoid the steric repulsion between the Pd center and the $\mathrm{R}^{1}$ group $\left(\mathrm{R}^{1}>>\mathrm{R}^{2}\right)$ by a $\pi-\sigma-\pi$ process. Intermediate 125 would further isomerizes to $\mathbf{1 2 6}$ because of the presence of the upper exo $\mathrm{C}=\mathrm{C}$ bond. The final product $\mathbf{1 2 1}$ is subsequently formed 20 by the Suzuki-type coupling of $\mathbf{1 2 7}$ with the organoboronic acid 120. It is presume that $\mathrm{K}_{2} \mathrm{CO}_{3}$ and the phosphine must promote this last step.

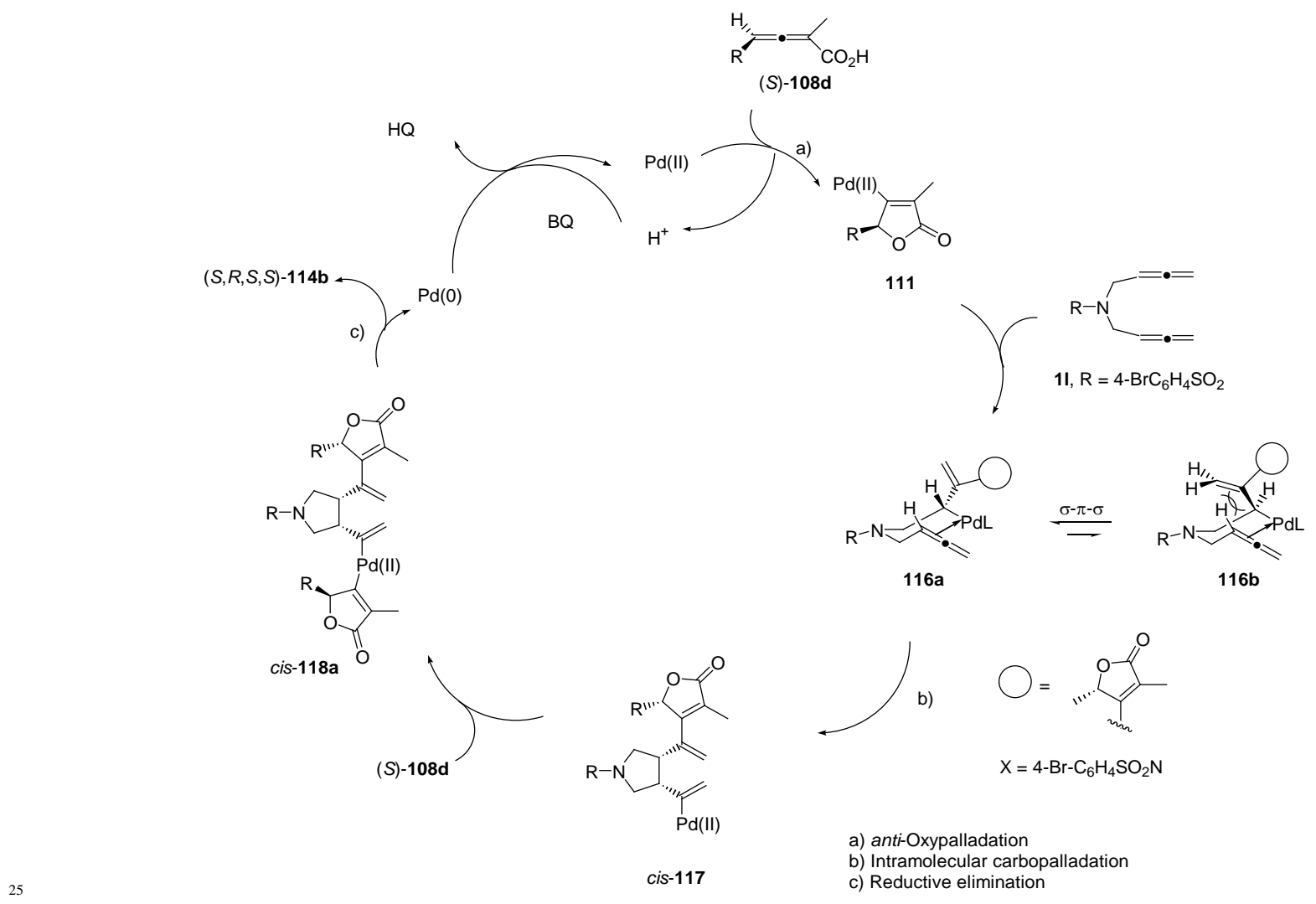

Scheme 45 Mechanistic explanation for the excellent chirality transfer observed in compound $(S, R, S, S)-\mathbf{1 1 4 b}$.

Scheme 46 Synthesis of compounds 121 via three component coupling of 1,5-bis(allenes) 1, propargyl carbonates 119 and phenyl boronic acids 120. 


\section{Cite this: DOI: $10.1039 / \mathrm{c0xx00000x}$}

As we discussed previously, propargyl carbonates are ideal starting substrates for the in situ generation of the allene functionality. Taking into consideration this transformation, a recent investigation describes the reaction of allene carbonates $5 \mathbf{1 2 8}$ in the presence of carbon nucleophiles, involving a bis(allene) intermediate. ${ }^{44}$ After screening a range of nucleophiles and reaction conditions, the authors found that the reaction of allene propargylic carbonates 128 with malonates using $5 \mathrm{~mol} \% \mathrm{Pd}\left(\mathrm{PPh}_{3}\right)_{4}$, 1.5 equivalents of $\mathrm{K}_{3} \mathrm{PO}_{4}$ in DMSO at $1070^{\circ} \mathrm{C}$ (or DMF at $90^{\circ} \mathrm{C}$ ) gave bicyclic compounds 129 in moderate to good yields (Scheme 48).

Compounds 129 could be formed by the mechanism shown in Scheme 49. First, oxidative addition of allene carbonate 128 with $\mathrm{Pd}(0)$ would afford the allenylpalladium intermediate $\mathbf{1 3 0}$,

15 which may undergo subsequent transformations by two possible pathways. Path A would involve intramolecular carbopalladation of the allene moiety which generate the allyl palladium species 131, which is attacked by the geminal bis(nucleophile) regioselectively due to a steric effect, to give 20 monocyclization product 132 with concomitant regeneration of the catalyst $\operatorname{Pd}(0)$. Further cyclization of the vinylallene $\mathbf{1 3 2}$ under basic conditions would then give compound 129. On the other hand, path $B$ would involve the attack of the allenylpalladium intermediate $\mathbf{1 3 0}$ by the geminal 25 bis(nucleophile) to form the intermediate 133, which then would undergo intramolecular carbopalladation of the allene moiety to furnish the $\pi$-allyl palladium species 134 , which is then attacked by the nucleophilic moiety under basic conditions to yield the bicyclic product 129 and regeneration of the $\operatorname{Pd}(0)$ 30 catalyst.

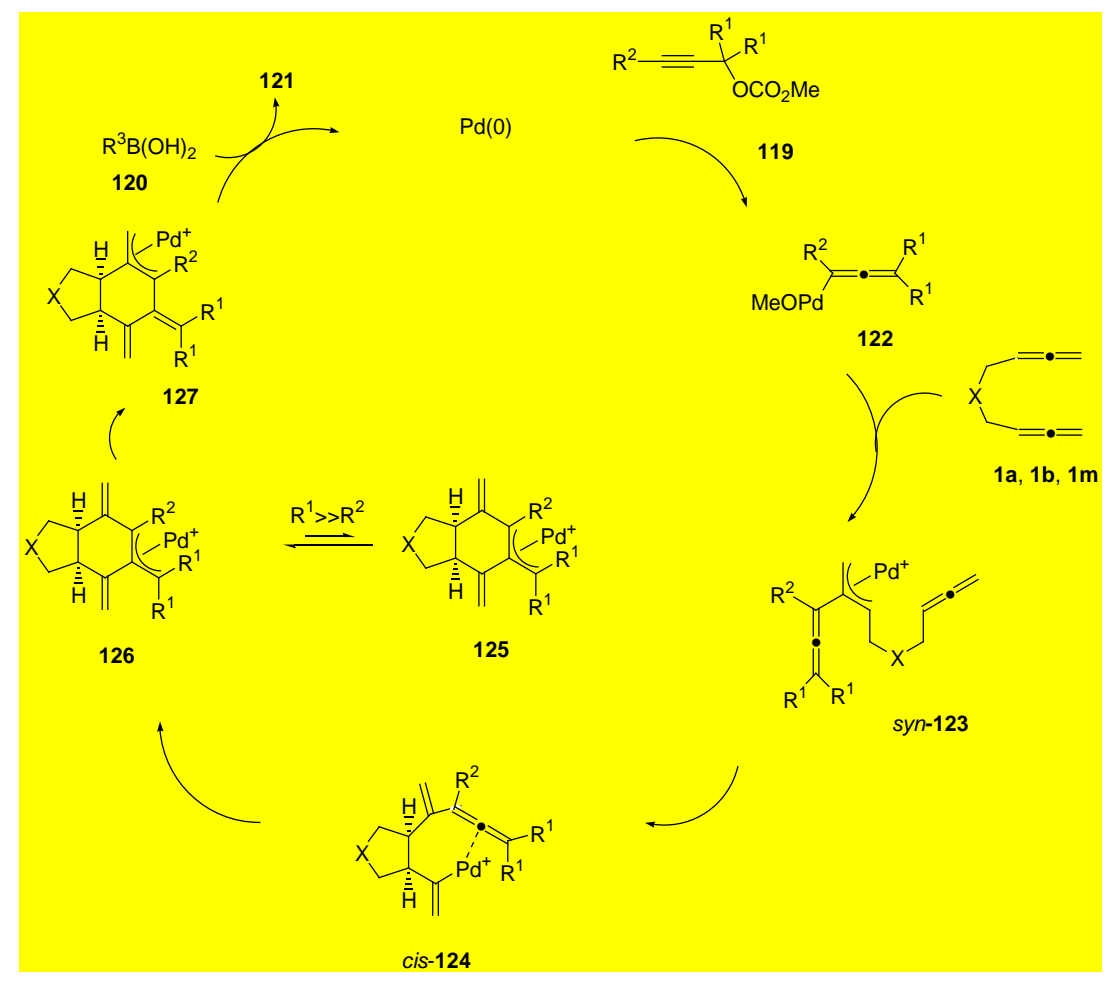

Scheme 47 Plausible mechanism for the formation of compounds 121. 
Cite this: DOI: 10.1039/c0xx00000x

www.rsc.org/xxxxxx

ARTICLE TYPE

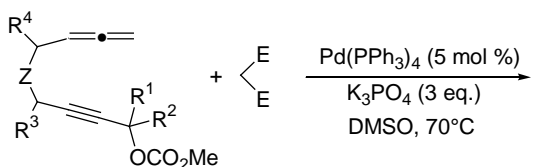

128

$\mathrm{Z}=\mathrm{NTs}, \mathrm{O}, \mathrm{C}\left(\mathrm{CO}_{2} \mathrm{Et}\right)_{2}$ $\mathrm{E}=\mathrm{CO}_{2} \mathrm{Me}, \mathrm{CO}_{2} t \mathrm{Bu}, \mathrm{COMe}, \mathrm{CN}$

$\mathrm{R}^{1}=\mathrm{Me}, \mathrm{Et}, \mathrm{BBu}, \mathrm{iPr}, \mathrm{Cy}$

$\mathrm{R}^{2}=\mathrm{H}, \mathrm{Me}, \mathrm{Et}$

$\mathrm{R}^{3}=\mathrm{H}, \mathrm{Pr}$

$\mathrm{R}^{4}=\mathrm{H}, \mathrm{Cy}, \mathrm{Ph}$

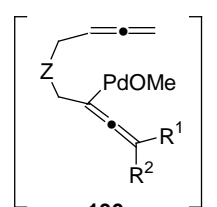

130

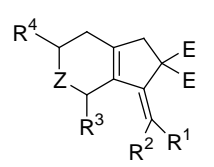

129

$51-85 \%$

Scheme 48 Synthesis of bicyclic compounds 129 from allene propargyl carbonates 128.

5 Scheme 49 Mechanistic proposal for the formation of compounds $\mathbf{1 2 9}$ from allene propargyl carbonates $\mathbf{1 2 8}$ involving the formation of bis(allene) intermediates $\mathbf{1 3 0 .}$

The synthesis of tetracenes 135 from bis(propargylic carbonates) 136 and organoborons catalyzed by $\operatorname{Pd}(0)$

10 involving the formation of a bis(allene) intermediate has been developed (Scheme 50). ${ }^{45}$ Reaction of compounds 136 with electron-neutral or electron-poor arylboronic acids in the presence of catalytic amounts of $\mathrm{Pd}\left(\mathrm{PPh}_{3}\right)_{4}$ afforded the corresponding tetracenes 135 in excellent yields. Although, two 15 regioisomers may be formed because both aryl groups in carbonate $\mathbf{1 3 6}$ and arylboronic acid might undergo ring-closure reaction, a single regioisomer was isolated. As discussed previously, the aromaticity of the final compounds explains why compounds $\mathbf{1 3 5}$ are isolated as single isomers. However, 20 when electron-rich arylboronic acids were employed, two regioisomers 135a and 135b were obtained. 


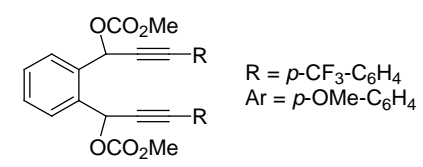

136

$\operatorname{ArB}(\mathrm{OH})_{2}(4$ equiv)

$\mathrm{Pd}\left(\mathrm{PPh}_{3}\right)_{4}(5 \mathrm{~mol} \%)$

THF, $50^{\circ} \mathrm{C}, 2.5 \mathrm{~h}$
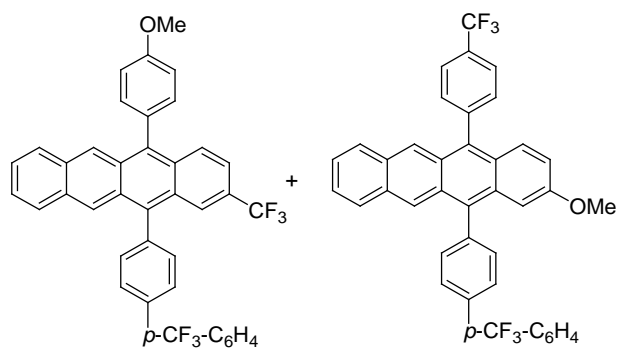

$135 a$

$40 \%$
Scheme 50 Synthesis of tetracenes 135 from dicarbonates 136 involving a bis(allene) intermediate.

A tentative mechanism has been proposed for this 5 transformation (Scheme 51). First, double $\mathrm{S}_{\mathrm{N}} 2^{\prime}$ attack of $\operatorname{Pd}(0)$ on the propargyl carbonate 136 would form bis[( $\sigma$ allenyl)palladium(II)] intermediate 137. 6- $\pi$-Electrocyclic ring closure of bisallene 137 would lead 2,3-naphtaquinodimethane 138 as the reactive alkene isomer, which can also be 10 represented as the resonance structure 139, a highly stabilized biradical. Then, disrotatory $6 \pi$-electrocyclization of naphthaquinodimethane $\mathbf{1 3 8}$ would occur to afford intermediate 140, in which the palladium and the hydrogen are in cis configuration. $\quad \beta$-Hydride elimination would furnish 15 arylpalladium intermediate 141. Suzuki-type coupling of intermediate 141 with an organoboronic acid would give the tetracene 135 and release of $\operatorname{Pd}(0)$. The formation of tetracene regioisomers 135a and 135b could be explained due to competitive coupling reactions of intermediates 137 or 138/139 20 with the arylboronic acid.

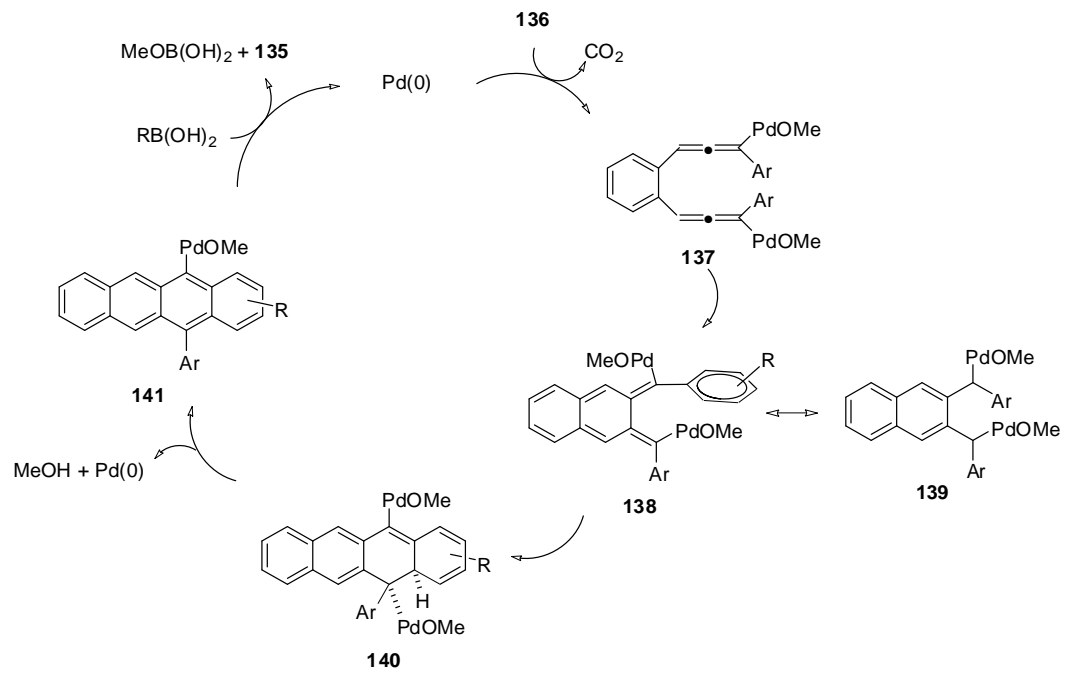

Scheme 51 Mechanistic explanation of compounds 135 involving a bis(allene) intermediate 137.

${ }_{25}$ Bis(allenes) 1 reacted with (trimethylsilyl)tributylstannane in the presence of a catalytic amount of $\mathrm{Pd}\left(\mathrm{PPh}_{3}\right)_{4}(5 \mathrm{~mol} \%)$ in refluxing THF, affording trans-fused cyclized compounds 142 in good yields. ${ }^{46}$ By contrast, when the same allenes $\mathbf{1}$ were treated with $\mathrm{Bu}_{3} \mathrm{SnSnBu}_{3}$, the $\mathrm{Pd}(0)$-catalyzed cyclization 30 process took place smoothly to afford cis-fused distannanes 143 (Scheme 52). Analogously, similar Pd-catalyzed cyclizations of 1,5-bis(allenes) with germylstannanes have been accomplished under the conditions described above. ${ }^{47}$ Thus, when $\mathrm{Y}$ group was $\mathrm{Bu}_{3} \mathrm{Ge}$, cis products 142 were obtained in ${ }_{35} 41-51 \%$ yields, while with $\mathrm{Y}$ being $\mathrm{Ph}_{3} \mathrm{Ge}$ group, trans products 143 were formed in $61-77 \%$ yields. In addition, in some cases, when the reaction time was prolonged to 12 hours, cis-fused bicyclic dienes 144 were isolated in low yield, formed via [2+2] cycloaddition of both terminal double bonds of the 40 bis(allene) (Scheme 52).

Formation of compounds 142 and 143 can be explained by the mechanism shown in Scheme 53. First, $\mathrm{Bu}_{3} \mathrm{SnPdY}$ species are generated via oxidative addition and then added to the allene 45 moiety. Next, the Y group is attached irreversibly to the central carbon of the allene, while palladatributyltin species added to the allene moiety to form complexes 145a and 145b, which undergone further cyclization with another allenyl group. Thus, the selectivity of cis and trans products must be controlled by 50 the steric effect between $\mathrm{Y}$ group and allene moiety in intermediates 146 or 147, respectively. When $\mathrm{Y}$ is a bulky group such as TMS or $\mathrm{GePh}_{3}$, trans products 142 are formed. However, when Y group is $\mathrm{SnBu}_{3}$ or $\mathrm{GeBu}_{3}$, formation of cis 
products $\mathbf{1 4 3}$ is favoured. It is important to remark that the steric hindrance of the TMS group compared to $\mathrm{Bu}_{3} \mathrm{Sn}$ is the shorter $\mathrm{Si}-\mathrm{C}$ bond length and a larger effective size. However, formation of cyclobutanes $\mathbf{1 4 4}$ must be explained via 5 palladacyclopentane intermediate $\mathbf{1 4 8}$, followed by reductive elimination.

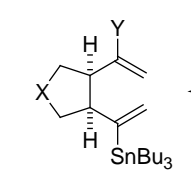

143

$\mathrm{Y}=\mathrm{SnBu}_{3}, 61-73 \%$

$\mathrm{Y}=\mathrm{GeBu}_{3}, 41-51 \%$
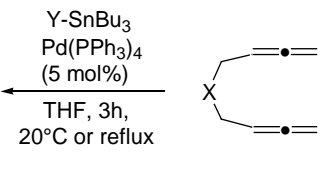

1a, 1c, 1n

$\mathrm{X}=\mathrm{NTs}, \mathrm{C}\left(\mathrm{CO}_{2} \mathrm{Et}\right)_{2}, \mathrm{C}(\mathrm{Ph})_{2}$

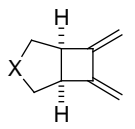

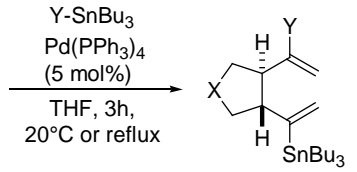

142

$\mathrm{Y}=\mathrm{TMS}, 71-78 \%$

$\mathrm{Y}=\mathrm{GePh}_{3}, 61-77 \%$

144

Scheme 52 Reaction of bis(allenes) 1 with (trimethylsilyl)tributylstannanes and with germylstannanes.

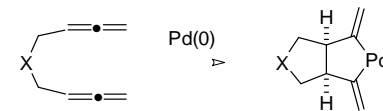

1a, 1c, 1n

148
$\mathrm{YSnBu}_{3} \quad \mathrm{Pd}(0)$

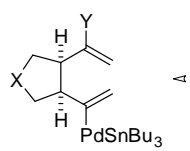

146

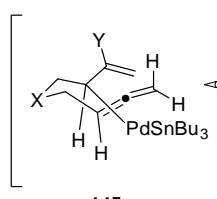

$145 a$

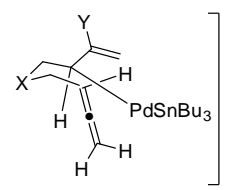

$145 b$

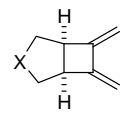

144

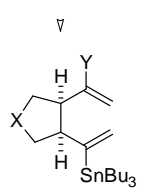

143

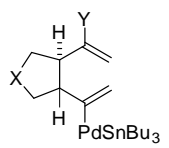

147

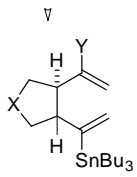

142

Scheme 53 Pd-catalyzed reaction of 1,5-bis(allenes) with $\mathrm{YSnBu}_{3}$.

15

Although for long time gold has been considered to be catalytically inactive, this metal has recently shown a rich coordination and organometallic chemistry, leading a high number of interesting contributions in both heterocyclic and 20 carbocyclic synthesis. ${ }^{48}$

In 2007, the cycloisomerization of enynes catalyzed by an NHC gold (I) catalyst to obtain tetracyclo[3.3.0.0. $\left.0^{2,8} .0^{4,6}\right]$ was reported. ${ }^{49}$ Based on this work, latter on, this group has reported the cycloisomerization reaction of bis(allenes) using 25 the same catalyst (Scheme 54). ${ }^{50}$ Cycloisomerization has been studied using $N$-substituted bis(allenes) 149 using $10 \mathrm{~mol} \%$ of [Au(IMes)Cl] $/ \mathrm{AgBF}_{4}$ as catalytic system affording compounds 150 in excellent yields. The presence of substituents on the internal double bonds of both allenyl groups did not inhibit the 30 desired reaction; however, the cycloisomerization did not tolerate substitution at the terminal allenyl carbon atom. Interestingly, although four possible compounds could be expected, namely head-to-head, tail-to-tail, head to tail and twisted head-to-head [2+2] cycloadducts, only the last ones 35 were obtained. To elucidate the formation of compounds $\mathbf{1 5 0}$, the authors carried out DFT calculations. From these calculations, the Au-catalyzed cycloisomerization reaction of bis(allenes) occurs via a stepwise process. Coordination of the gold salt to the allene moiety to give $\mathbf{1 5 1}$ is followed by the 40 nucleophilic attack of the other allenyl group to the gold-bound allene, with concominant formation of a $\mathrm{C} 1-\mathrm{Au}-\mathrm{C} 2$ ' bridge forming intermediate 152. The positive charge must be stabilized by the gold atom, facilitating the formation of $\mathrm{C}-\mathrm{C}$ 
bond between $\mathrm{C} 1$ and $\mathrm{C}^{\prime}$ ' in intermediate 152, which would afford 6,7-dimethyleneazabicyclo[3.1.1] heptane skeleton 150 from intermediate 153 (Scheme 55).

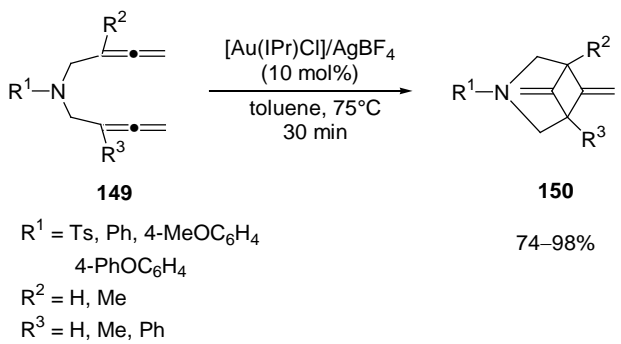

5 Scheme 54 Transformation of $N$-tethered 1,5-bis(allenes) to compounds 150.

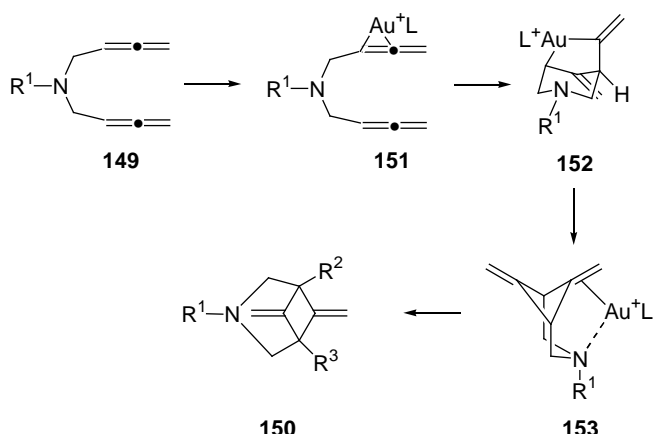

Scheme 55 Proposed catalytic mechanism for the synthesis of compounds 150 .

While the olefin metathesis reaction has experienced spectacular achievements in organic synthesis with interesting applications in natural product synthesis, ${ }^{51}$ the olefin metathesis in allenes has been scarcely investigated and in the examples 15 described so far, the final compounds have been isolated in very low yields. ${ }^{52}$ It is presume that both, formation of very large size rings and conformational disposition of the starting material, are the main factors involved in the poor results obtained. Thus, during the studies of ring closing metathesis 20 (RCM) between alkenes and allenes in order to obtain cyclophanes, the synthesis of allenic macrocycles by treatment of $\alpha, \gamma$-bis(allenes) 154 and 155 with Grubbs'first generation catalyst under high dilution conditions was reported (Scheme 56). ${ }^{53}$ Thus, the desired 15- and 17-membered allenes 156 were 25 isolated in reasonable yields. However, the analogous bis(allene) bearing an aromatic speacer afforded allenic cyclophane 157 with only $9 \%$ yield.

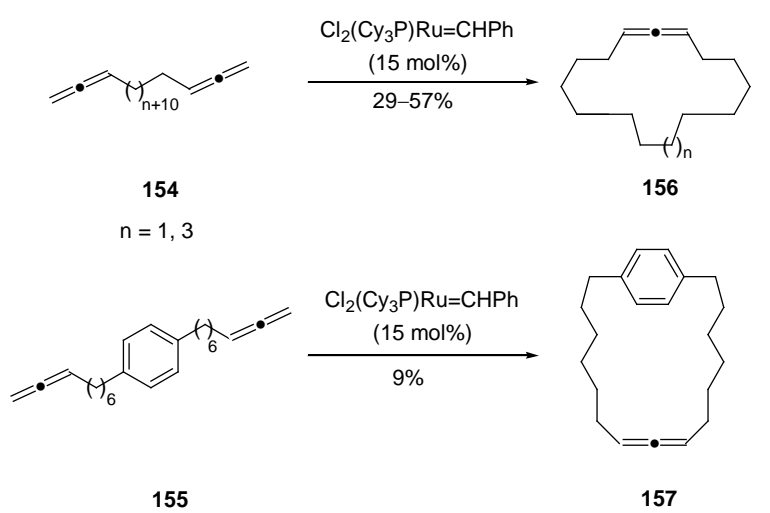

Scheme 56 Ring closing metathesis of compounds 154 and 155.

30 During the studies on the transannular intramolecular [4+3] cycloaddition reaction, en route to the ABCD ring structure of cortistatins, ${ }^{54}$ it has been studied the RCM of bis(allenes). RCM of bis(allene) 158 using Grubbs'first generation catalyst under high dilution conditions gave allenic macrocycle 159 in $47 \%$ 35 yield (Scheme 57). Transannular [4+3] cycloaddition was achieved by treatment of allene 159 with $10 \mathrm{~mol} \% \mathrm{Pd}(\mathrm{OAc})_{2}$ in the presence of $\mathrm{LiBr}$ to give compound $\mathbf{1 6 0}$ in 37\% yield.

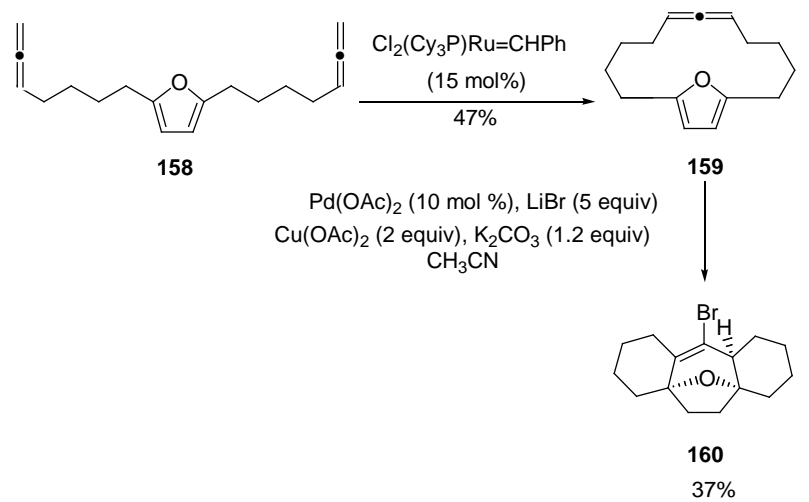

Scheme 57 Synthesis of the ABCD ring core of cortistatins via RCM of 40 compounds 158 followed by [4+3] cycloaddition.

The potential and utility of radical reactions in the construction of carbocyclic and heterocyclic compounds has been widely demonstrated. ${ }^{55}$ Concerning the reactivity of allene derivatives, 45 for long time, this peculiar functionality have been discriminate against radical processes due to the lack of chemo-, regio-, and stereoselectivity. However, in recent years, interest in radicalbased transformations of allenes has been revitalized due to the accomplishment of the synthesis of target molecules and the 50 results obtained from theoretical investigations. Radicals derived from allenes undergo cyclizations related to those of their olefinic counterparts. ${ }^{56}$ The efficiency of this transformation depends on the chain length separating both reactive entities and is the major factor for regiocontrol. Thus,

55 radical cyclization can takes place on the central carbon atom via the dig mode of ring closure or to the internal carbon atom via the trig mode of ring closure.

Reaction of bis(allenes) 1 with $p$-tosyl bromide or $p$ tosylseleniumbromide in the presence of a catalytic amount of 60 AIBN afforded trans-fused cyclopentane compounds 161, 
incorporating vinyl sulfones, vinyl bromides or selenophenyl functionalities in their structure (Scheme 58). ${ }^{57}$ The addition of tosyl radical to the central carbon atom of one allene moiety gives an allylic radical intermediate 162. This propagation step 5 is followed by cyclization with the other tethered allene moiety in a stereoselective trans fashion in radical $\mathbf{1 6 2}$ to give intermediate 163. Finally, intermediate 163 is trapped by the corresponding bromide or selenophenyl radicals to afford the energetically more favorable and more stable trans product 10161.

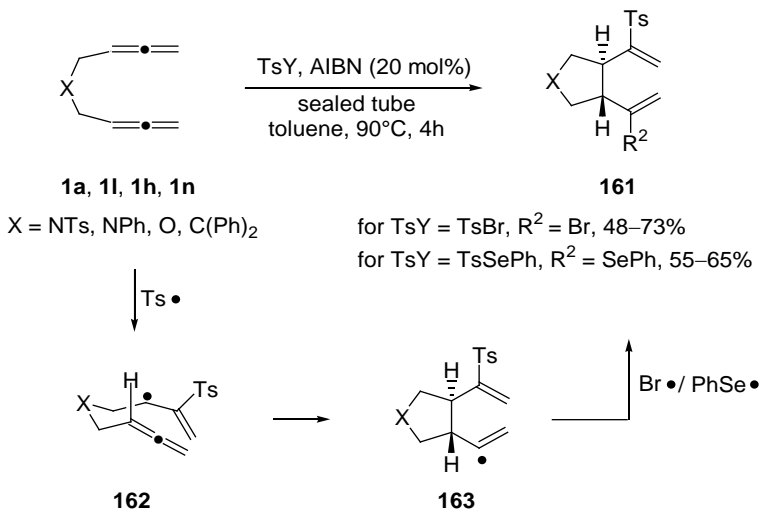

Scheme 58 Synthesis of trans-fused cyclopentane compounds 161 from bis(allenes) 1 via a radical mechanism.

15 The Garratt-Braverman cyclization is a multistep process which involves a diradical intermediate, which collapse to the final product via self-quenching, forming two new $\mathrm{C}-\mathrm{C}$ bonds. In a recent work, it has been reported the synthesis of 1-indol-3-ylcarbazoles 164 via Garratt-Braverman cyclization, involving 20 bis(allene) intermediate 165 and diradical intermediate 166 (Scheme 59). ${ }^{58}$ The corresponding bis(indoles) were prepared from indole or indole derivatives. The Garratt-Braverman cyclization was studied in compounds 167 using $\mathrm{Et}_{3} \mathrm{~N}$ in $\mathrm{CDCl}_{3}$. The reaction with bis(indole) sulfone was more 25 successfully accomplished using DBU, thus compound 164 was obtained in $80 \%$ yield. In addition, cyclization of bis(indole) ether and bis(indole) amine were successfully achieved using $\mathrm{KO}^{\mathrm{t}} \mathrm{Bu}$ in refluxing toluene, affording both indolyl derivatives $\mathbf{1 6 4}$ in $75 \%$ yield. It is important to note that 30 during the cyclization step of the radical intermediate 166 to compounds $\mathbf{1 6 4}$, isomerization of the six membered-ring takes place.

Latter on, a related research work has studied the competition between $6 \pi$-electro- and Garratt-Braverman cyclizations in 35 bis(allene) sulfones. ${ }^{59}$ Thus, reaction of bis(alkyne) sulfones 168 in the presence of $10 \mathrm{~mol} \%$ of $\mathrm{Et}_{3} \mathrm{~N}$ afforded a mixture of Garratt-Braverman products $\mathbf{1 6 9}$ as major products along with $6 \pi$-electrocyclization products $\mathbf{1 7 0}$ (Scheme 60). It has been observed that increasing the steric bulk of the $\mathrm{R}^{2}$ group has a 40 minimal effect on the selectivity of the reaction. However, lowering the temperature of the reaction favoured the formation of compound 169 (kinetic product), while higher temperature favoured the $6 \pi$-electrocyclization compound $\mathbf{1 7 0}$ (thermodynamic product). Formation of compounds 169 has 45 been explained via bis(allene) intermediate $\mathbf{1 7 1}$ and diradical 172.

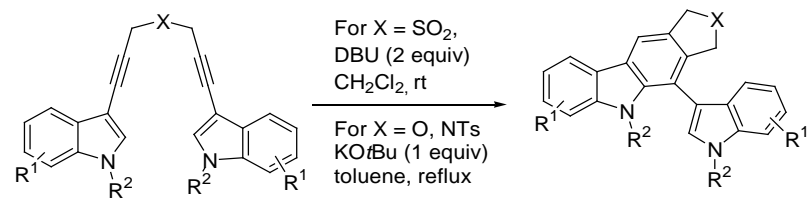

167

164

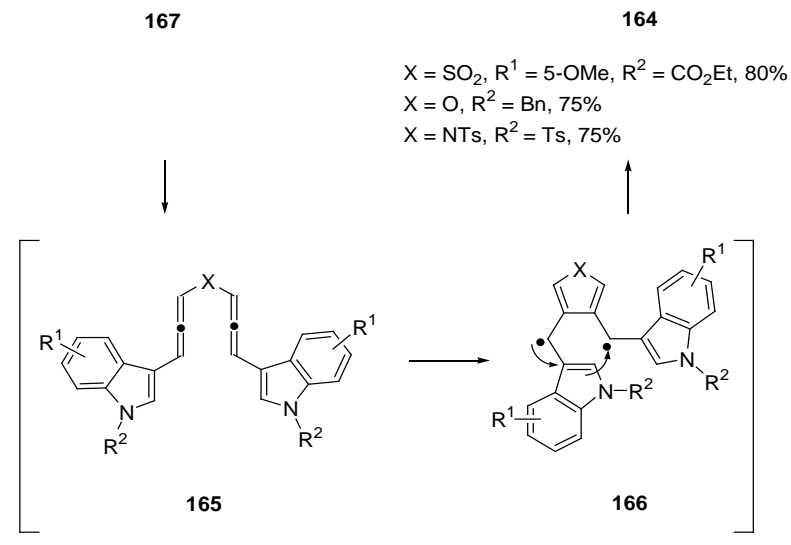

50 Scheme 59 Synthesis of 1-indol-3-yl-carbazoles 164 via the GarrattBraverman cyclization, involving the formation a bis(allene) intermediate 165.

\subsubsection{Reactivity Allene-Non Allene}

Recently, the synthesis of carbazoles and bis(carbazoles) from 55 indole-C2-tethered allenols under mild conditions has been reported. ${ }^{60}$ Although NH-indole-tethered allenols have diverse reactive sites, at which different transformations (C-cyclization versus $\mathrm{O}$-cyclization versus $\mathrm{N}$-cyclization) can take place, carbocyclization products have been exclusively obtained. 60 Besides, reaction of bis(allenes) $\mathbf{1 7 3}$ with allyl bromides under palladium catalysis afforded bis(carbazoles) $\mathbf{1 7 4}$ in reasonable yields (Scheme 61).

A likely mechanism for the palladium-catalyzed generation of functionalized carbazoles $\mathbf{1 7 4}$ is outlined in Scheme 62. First, ${ }_{65} \mathrm{Pd}(\mathrm{II})$ coordination to both allene moieties would give a bis(allenepalladium) complex 175. Species 175 would suffer a two-fold intramolecular chemo- and regioselective 6-endo carbocyclization reaction to give an intermediate bis(palladadihydrocarbazole) 176, which would react with two 70 equivalents of the allyl bromide via $\mathbf{1 7 7}$ to form intermediate 178. A double trans- $\beta$-heteroatom elimination with concurrent dehydration under the reaction conditions generates carbazoles of type 174 with concomitant regeneration of the $\mathrm{Pd}(\mathrm{II})$ catalyst. Apparently, HX would promote the dehalopalladation, 75 inhibiting the $\beta$-H elimination. 

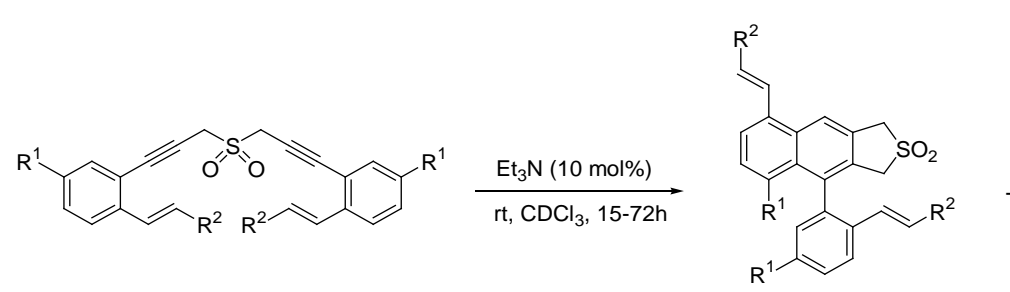<smiles>[R1]c1ccc2cc(CSCc3cc4cc([R])ccc4cc3[R])c([R])cc2c1</smiles>

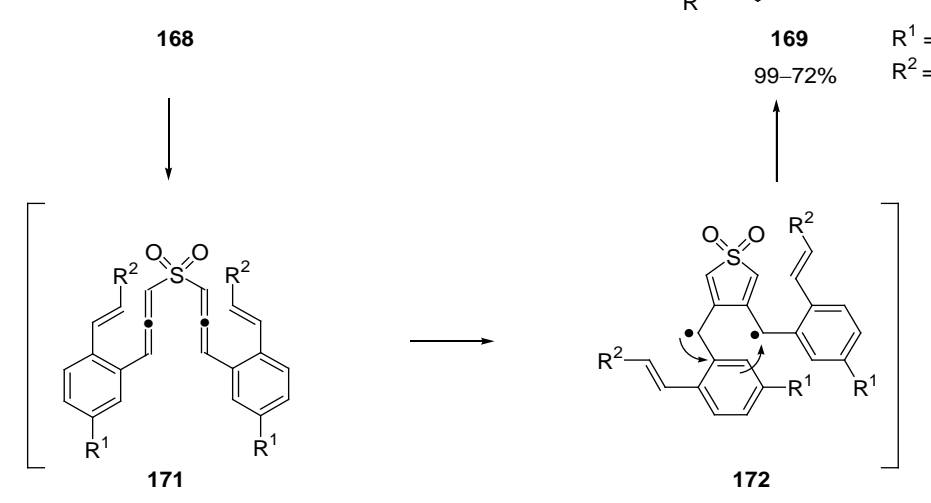

Scheme 60 Formation of compounds 169 and 170 via $6 \pi$-electro and Garratt-Braverman cyclizations of compounds 168 involving formation of bis(allenes) intermediates 171.

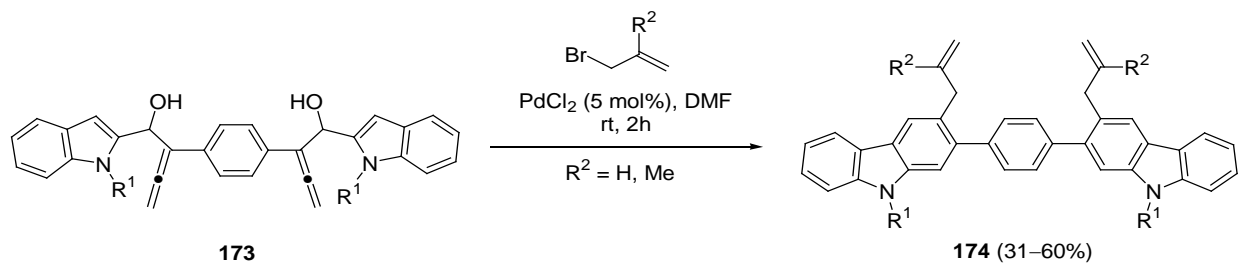

$\mathrm{R}^{1}=\mathrm{H}, \mathrm{Me}$

Scheme 61 Synthesis of bis(carbazoles) 174 via carbocyclization of bis(allenes) 173.<smiles>[R]C(=C)Cc1cc2c(cc1-c1ccc(-c3cc4c(cc3CC([R])=C)c3ccccc3n4[R])cc1)c1ccccc1n2[R]</smiles>

174

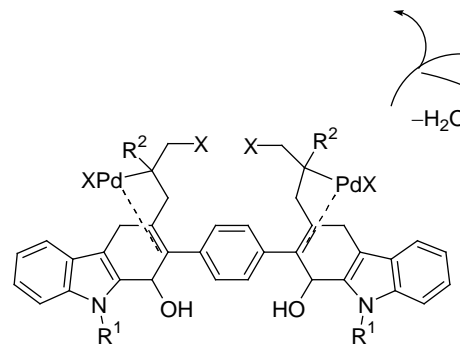

178

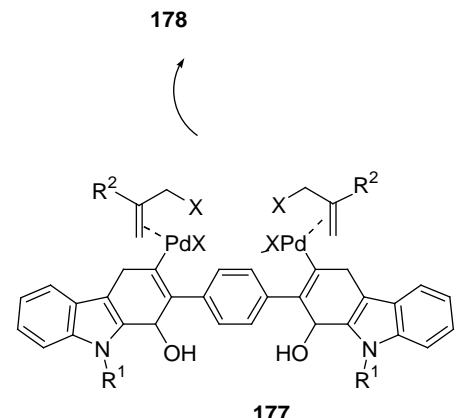<smiles>[Y19]n1c(C(O)C(=C)c2ccc(C(=C)C(O)c3cc4ccccc4n3[R1])cc2)cc2ccccc21</smiles>

173<smiles>[Y20]C=C(c1ccc(C(=C([Y20])[Y20])C(O)c2cc3ccccc3n2[R1])cc1)C(O)c1cc2ccccc2n1[R12]</smiles>

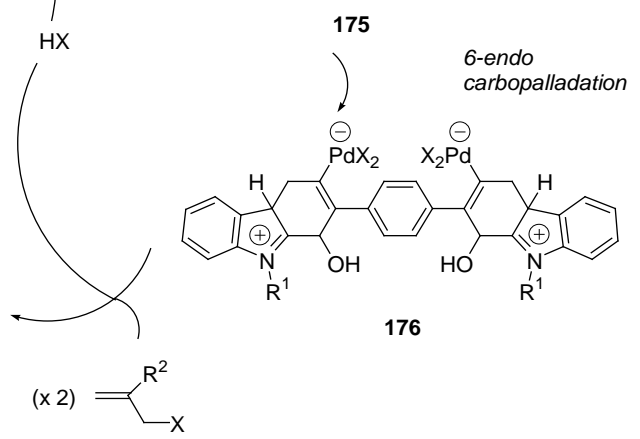

Scheme 62 Suggested mechanism for the formation of functionalized carbazoles $\mathbf{1 7 4}$ from bis(allenes) 173. 


\section{Cite this: DOI: 10.1039/c0xx00000x}

\section{www.rsc.org/xxxxxx}

An alternative mechanism to form bis(carbazoles) 174 could also be proposed (Scheme 63). First, oxidative addition reaction of the allyl bromide with palladium would form a $\pi$ allyl palladium complex 179, which would add to the central 5 carbon of the 1,2-diene moiety through carbopalladation, giving rise to a new bis( $\pi$-allyl palladium) complex 180 . Intermediate 180 would evolve through double intramolecular 6-endo carbocyclization reaction, with concomitant dehydration, to give functionalized bis(carbazoles) with 10 regeneration of the palladium species.

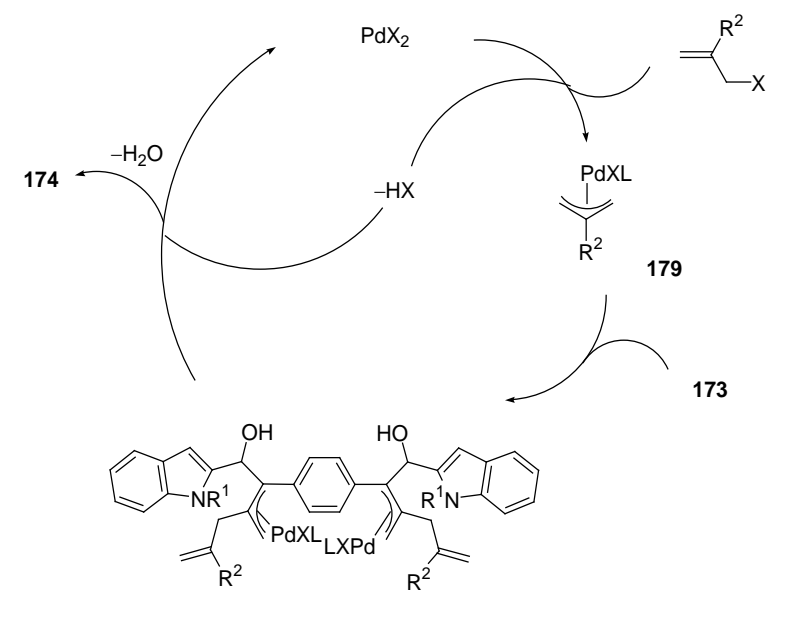

180

Scheme 63 An alternative mechanism for the formation of functionalized carbazoles $\mathbf{1 7 4}$ from bis(allenes) 173.

The electrophilic addition of allenes has not been studied in 15 detail due to the difficulty to control the stereoselectivity of the final compounds. There are recent examples concerning the electrophilic interaction of 1-substituted 2,3-allenols with $\mathrm{Br}_{2}$, NBS and $\mathrm{I}_{2}$, affording 3-halo-3-alkenals or 2-halo-2-alkenyl ketones in good yields. ${ }^{61}$ In this context, it has been reported 20 the ring expansion of bis( $\beta$-lactam)-bis(allenes) into bis(tetramic acids) in the presence of $N$-bromosuccinimide (NBS). ${ }^{62}$ Thus, reaction of bis( $\beta$-lactam)-bis(allene) 181 with one equivalent of NBS afforded compound 182 via selective ring expansion of one $\beta$-lactam ring (Scheme 64). The use of 3 25 equivalents of NBS smoothly afforded bis(tetramic acid) 183 formed via double ring expansion of both $\beta$-lactam rings in compound 181.

ARTICLE TYPE

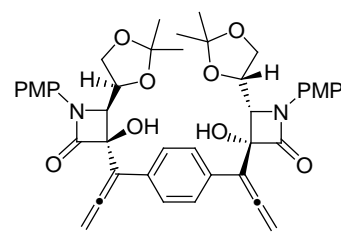

181
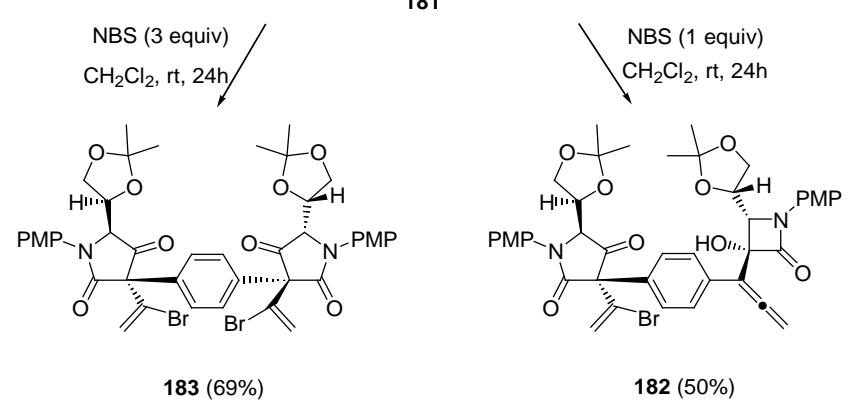

30 Scheme 64 Synthesis of tetramic and bis(tetramic acids) 182 and 183, respectively via NBS addition to bis(allene) $\mathbf{1 8 1}$.

To understand the mechanism of the ring expansion of compounds 181 promoted by NBS, the mechanism of the reaction has been investigated using DFT methods. Thus, the 35 ring expansion of compound $\mathbf{1 8 1}$ to $\mathbf{1 8 3}$ could be explained via one-step mechanism involving the addition of $\mathrm{Br}^{+}$from NBS to the central sp carbon atom of both allene groups, followed by double ring expansion (Scheme 65). This path would involve a double carbocationic intermediate with hydrogen bonds 40 between one oxygen atom of NBS and the hydroxylic hydrogen atoms. Although two stereoisomers could be formed via transition states 184 and 185, which have similar energies, the presence of a bulky substituent $\left(\mathrm{R}^{2}\right)$ is the responsible to control the stereoselectivity of the reaction. In addition, 45 formation of compounds $\mathbf{1 8 3}$ could be explained in two steps, which would involve a single ring expansion of one allene moiety and subsequent ring expansion of the second allene functionality in compound $\mathbf{1 8 1}$.

\subsection{Formation of new C-heteroatom bonds: ${ }_{50}$ Heterocyclizations}

Allenes containing a nucleophilic functional group, such as oxygen or nitrogen, are versatile synthetic building blocks for the construction of different heterocycles depending on the nature of the nucleophilic center. ${ }^{63,64}$ In particular, 55 cycloisomerization of $\alpha$-hydroxyallenes afford 2,5dihydrofurans, which are present in biologically active compounds, ${ }^{65}$ and are excellent building blocks in organic synthesis. ${ }^{66}$ This cycloisomerization reaction takes place with axis-to center chirality transfer when the reaction is promoted 60 by anhydrous acid, ${ }^{67}$ silver, ${ }^{68,69,70}$ or gold salts. ${ }^{71,72,73}$ In addition, this transformation has been studied using $\mathrm{Pd}(\mathrm{II})$ 
catalyst to

obtain the corresponding 2,5-dihydrofurans

smoothly. $^{74}$

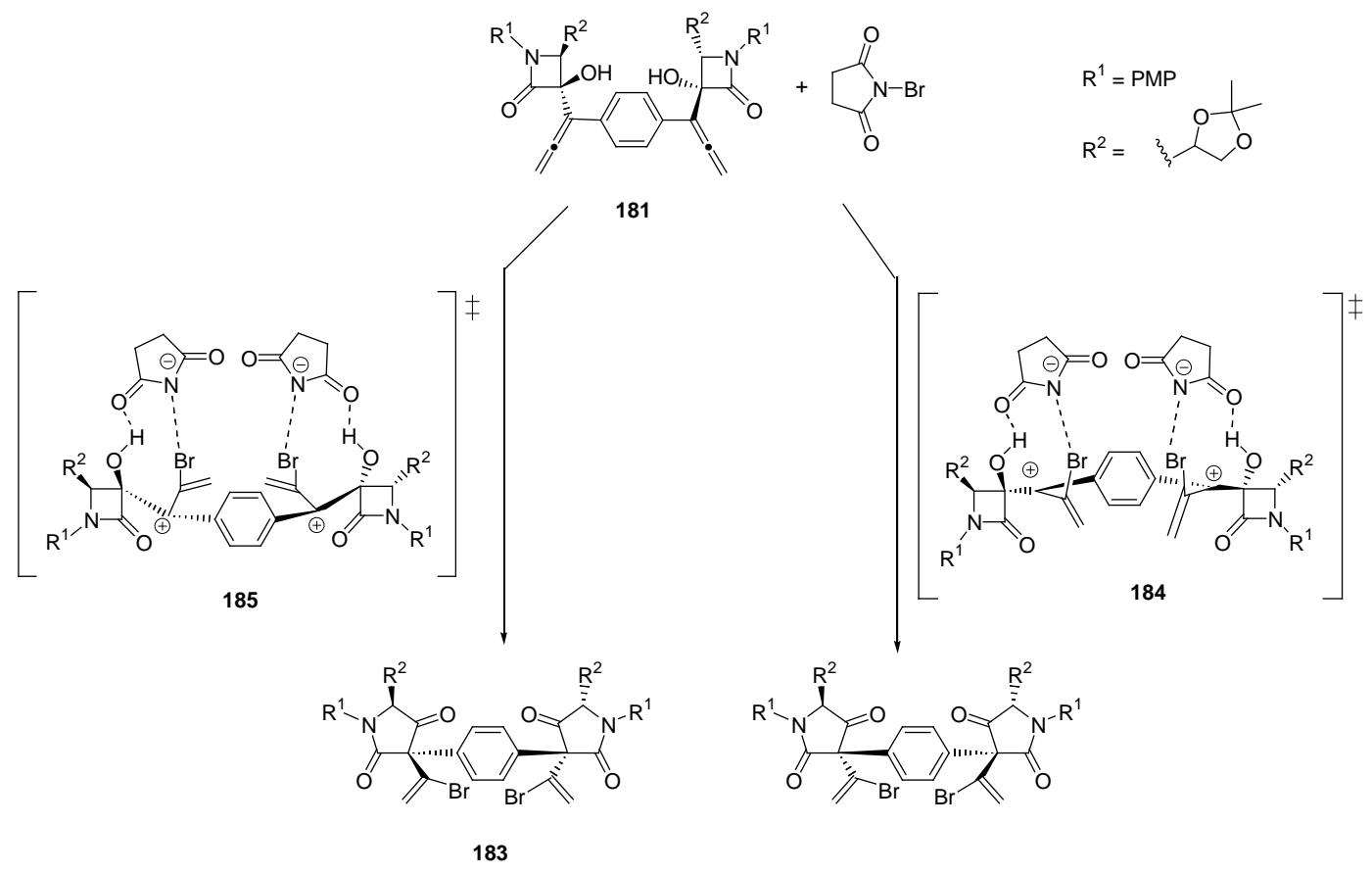

Scheme 65 Mechanistic proposal for the ring expansion of compounds 181. 


\section{Cite this: DOI: $10.1039 / \mathrm{c0xx00000x}$}

A reasonable mechanism would involve metal coordination to one allenic double bond, followed by nucleophilic attack to generate a metalloheterocycle. Subsequent protonolysis of the carbon-metal bond would then yield the product and regenerate 5 the catalyst (Scheme 66).

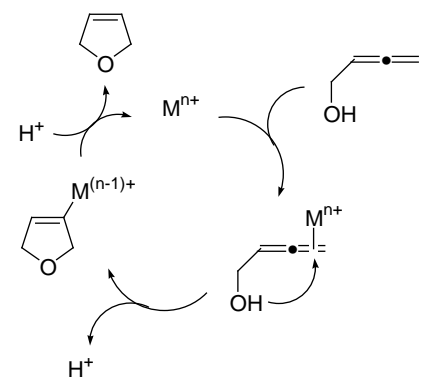

Scheme 66 General mechanism for the cycloisomerization of $\alpha$ hydroxyallenes to afford 2,5-dihydrofurans.

10 Taking advantage of this cycloisomerization process, this methodology has been applied to the synthesis of bis(2,5dihydrofurans). Thus, the synthesis of bis(2,5-dihydrofuran) derivatives 186 by silver- or gold-catalyzed cycloisomerization of bis( $\alpha$-hydroxyallenes) 187 with axis-to-center chirality transfer 15 has been reported. ${ }^{75}$ First, conjugated bis(allenes) 187 have been synthetized via copper mediated $\mathrm{S}_{\mathrm{N}} 2$ '-substitution of bis(propargyloxiranes) 188. Compounds 188 are a mixture of the meso- and dl-diastereomers. Interestingly, each propargyloxirane can be subjected to a syn- or anti- selective $\mathrm{S}_{\mathrm{N}} 2$-substitution. 20 Thus, 8 diastereomeric bis(allenes) could be formed in the reaction. Interestingly, in the event, only a single diastereomer has been obtained. However, the relative configuration of bis(allenes) 187 has not been assigned because these compounds were not crystalline. The cycloisomerization processes have been 25 studied using gold and silver catalyst. Reaction of bis(allenes) 187 in the presence of silver nitrate gave the corresponding functionalized bis(2,5-dihydrofurans) $\mathbf{1 8 6}$ in moderate yields. However, the reaction of the bis(allene) $\mathbf{1 8 7}$ with an internal substituent more bulky such as $i \mathrm{Pr}$, in the presence of silver 30 nitrate, induced a rapid monocyclization to afford the corresponding 2-allenyl-substituted 2,5-dihydrofurans 189 with excellent yield as single diastereomers with axis-to-center chirality transfer (Scheme 67). Fortunately, the second cyclization step was achieved by the combined used of $N$ 35 iodosuccinimide and gold-catalysis. Then, reaction of allenes $\mathbf{1 8 9}$ with $2 \mathrm{~mol} \%$ of gold(III) bromide in the presence of 1.2 equiv of NIS in dichloromethane at room temperature afforded the richly functionalized bis(2,5-dihydrofuran) 190 in $61 \%$ yield.
40 Scheme 67 Silver and gold-catalyzed cycloisomerization of bis(allenes) 187.

A few years ago, it was reported the cyclization of 2,3-allenoic acids in the presence of 2,3 -allenols, ${ }^{76}$ as well as the 45 palladium(II)-catalyzed heterocyclization/cross-coupling reaction between an $\alpha$-allenol and a ester protected $\alpha$-allenol. ${ }^{77,78}$ Besides, the cyclization of one 2,3-allenol in the presence of a different ${ }^{79}$ or the same ${ }^{80}$ 2,3-allenol, affording 4-(1',3'-dien-2'-yl)-2,5dihydrofurans has been described. ${ }^{81}$

50 Taking into account this process, it has been reported the synthesis of 2,5-dihydrofuran-fused bicyclic skeletons via intramolecular $\mathrm{Pd}(\mathrm{II})$-catalyzed cyclization of 1, $\omega$-bisallenols, where one hydroxyl group can be protected as acetate. ${ }^{82}$ Thus, reaction of bis(allenols) 191 in the presence of $\mathrm{PdCl}_{2}$ (5 mol\%) 55 has provided the corresponding fused bicycles[5.3.0] 192 in moderate to good yields (Scheme 68). It is important to mention the importance to protect one of the hydroxyl groups as acetate for non symmetric bis(allenols), otherwise a complex reaction mixture is observed. 
Scheme 68 Synthesis of 2,5-dihydrofuran-fused bicyclic skeletons via Pd(II)-catalyzed tandem-cyclization of bis(allenols) 191.

Formation of 1,5-dihydrofuran-fused bicyclic skeletons 192 has 5 been rationalized by the mechanism shown in Scheme 69. First, oxypalladation of the 1,3-allenol moiety in 191 would form intermediate 193. Then, regioselective intramolecular carbopalladation of the remaining allene unit in 193 would form the $\pi$-allylic palladium intermediate 194. Subsequent trans- $\beta$ 10 hydroxide or acetate elimination would afford products 192 highly stereoselective.

Scheme 69 Mechanistic proposal for the synthesis of 1,5-dihydrofuranfused bicyclic skeletons 192.

15 Following observations on allenyl alcohols, it was studied the cycloisomerization of allenyl ketones and allenyl aldehydes 195 to afford substituted furans $196 .{ }^{70}$ Initially, this transformation has been developed using stoichiometric quantities of $\mathrm{Ag}(\mathrm{I})$ salts such as $\mathrm{AgNO}_{3}$ and $\mathrm{AgBF}_{4}$. Further studies allowed the reaction 20 using catalytic conditions (0.1-0.2 equiv) (Scheme 70).
${ }_{25}$ Scheme 70 Cycloisomerization reaction of allenyl ketones and allenyl aldehydes in presence of stoichiometric quantities of $\mathrm{Ag}(\mathrm{I})$.

Interestingly, the reaction of allenone 197 in the presence of palladium catalyst involving a combination of $\mathrm{C}-\mathrm{O}$ and $\mathrm{C}-\mathrm{C}$ bond formation, afforded compound $\mathbf{1 9 8}$ as the major product 30 with a small amount of furan 199 (Scheme 71). ${ }^{83,84}$ Compound 200 was observed as side-product under non-optimized conditions and compound 201 was not isolated.

Scheme $71 \mathrm{Pd}(\mathrm{II})$-catalyzed isomerization of allenones to afford furans.

35

Latter on, it was investigated the application of this methodology to the formation of macrocyclic furanophanes from bis(allenylketones) as starting materials. In fact, reaction of bis(allenones) 202 catalyzed by $\left[\mathrm{PdCl}_{2}\left(\mathrm{MeCN}_{2}\right]\right.$ afforded a 40 mixture of four different products (Scheme 72): a) 1,ndifurylalkanes 203 formed by Marshall reaction (analogous to compounds 196 in Scheme 70); b) furanophanes 204, having an (E)-configuration of the alkene in the bridge, formed by Pdcatalyzed intermolecular coupling of allenyl ketones (analogous 45 to compounds 198 in Scheme 71); c) furanophanes 205, with a (Z) configuration of the alkene in the bridge, curiously not observed previously in the intermolecular couplings; and d) furanophanes 206, having an exocyclic double bond. Interestingly, formation of each compound or a mixture of some 50 of them depends on the length of the tether between both carbonyl groups. Thus, it has been observed that with a short bridge of four or five methylene units, no macrocycles were formed and only difurylalkanes 203 were obtained. A bridge of six to eight methylene units gave compounds 203, a small amount 55 of compound 204 (1\% in all cases), while compounds 205 are the major products and the proportion of 206 increases sequentially. With ten and eleven methylene units, the trend remains for compounds 203 and 204, which are the major products, while the amounts of $\mathbf{2 0 5}$ and 206 decreased sharply. Finally, with $\mathrm{n}=12$ 60 and 14, compound 204 was the only macrocycle observed. Thus, formation of compounds depends on the length of the bridge. For long bridges, the meta bridging of the furan ring and the $(E)$ configuration of the double bond in this bridge are tolerated without difficulties. However, for $n=5-8$, the strain seemed to 65 increase; then the double bond geometry in the bridge switches to the $(Z)$ configuration, favoring formation of compounds 205. 
Cite this: DOI: $10.1039 / \mathrm{c0xx00000x}$

www.rsc.org/xxxxxx

ARTICLE TYPE

Scheme 72 Pd-catalyzed cycloisomerization reaction of bis(allenones) 202.

\begin{abstract}
5 More recently, it has been investigated the transition metalcatalyzed biscyclization of 1,5-bis(1,2-allenylketones) $207 .{ }^{85}$ There are four different possibilities: a) formation of compound 208 by bis(cycloisomerization) of each allenone moiety; b) formation of bicyclic compounds 209 and 210, analogous to 10 compounds 204 and 206 (in Scheme 72); and c) tricyclic products 211 (Scheme 73).
\end{abstract}

\footnotetext{
Scheme 73 Metal-catalyzed biscyclization of 1,5-bis(1,215 allenylketones) 207.

Initially, the reactivity of symmetrical 1,5-bis(1,2allenylketones) 207a was tested using $5 \mathrm{~mol} \%$ of [PdCl$\left(\mathrm{PeCN}_{2}\right]$, affording furo[3,4-c]azepine derivative 209a together with the $\mathrm{C}=\mathrm{C}$ bond regioisomer 210a in 90:10 ratio in ${ }_{20} 68 \%$ yield (Scheme 74). After variation of several parameters in order to improve the selectivity of the cyclization process, the optimum catalyst was found to be $\left[\mathrm{RhCl}(\mathrm{CO})_{2}\right]_{2}$ (Scheme 75). In addition, unsymmetrical diketones 211 selectively afforded the expected cyclization products 212 in moderate to 25 good yields with a small amount of compound 210 in some cases (Scheme 76).
}

Scheme 74 Palladium(II)-catalyzed cyclization of 1,5-bis(1,2-
allenylketone) 207a.

30

Scheme 75 Rhodium(I)-catalyzed cyclization of symmetrical 1,5bis(1,2-allenylketones) 207.
35

Scheme 76 Rhodium(I)-catalyzed cyclization of non-symmetrical 1,5bis(1,2-allenylketones) 211. 
Formation of the 3,4-fused bicyclic furo-skeletons has been rationalized by the mechanism shown in Scheme 77 . First, the cyclic oxymetalation of the 1,2-allenyl ketones moietes in $\mathbf{2 0 7}$ and 211 catalyzed by Pd (II) or Rh (I) would form intermediate $5214(\mathrm{M}=\mathrm{Pd}$ or $\mathrm{Rh})$. The electron-donating $\mathrm{R}^{1}$ group increases the nucleophilicity of the carbonyl oxygen atom; explaining the selectivity for unsymmetrical substrates. Then, intramolecular carbometalation of the remaining allene unit in $\mathbf{2 1 4}$ would form $\pi$-allylic palladium intermediate $\mathbf{2 1 5}$ due to the low 10 oxophilicity of palladium. Due to the presence of the carbonyl compound, subsequent protonolysis of $\mathbf{2 1 5}$ with $\mathrm{H}^{+}$may occur. However, such a reaction at the $\alpha$ - or $\gamma$-position would afford an isomeric mixture of 209 and 210, being 209 the major product due to steric effects. Finally the catalytically active ${ }_{15} \mathrm{Pd}(\mathrm{II})$ species is regenerated. By contrast, oxygen-bound rhodium dienolate intermediates $\mathbf{2 1 6}$ must have formed exclusively using the rhodium catalyst. Therefore, the only observed products are 209 and 212.
20

Scheme 77 Plausible mechanism for the formation of compounds 209 , 210 and 212.

Medium-sized heterocycles are an important class of compounds which are found in a variety of natural products, 25 however they are difficult to prepare due to entropic and enthalpic reasons. ${ }^{86}$ On the other hand, Pd-catalyzed carbopalladation of allenes may afford the $\pi$-allyllic palladium species which can react with a nucleophile to form the allylation product (Scheme 79).

Scheme 78 Formation of allylation products via Pd-catalyzed carbopalladation of allenes.
It has been reported both the inter- ${ }^{87}$ and intramolecular ${ }^{88}$ threecomponent reactions between allenes, amines and aryl iodides. ${ }_{35}$ This transformation could be explained via oxidative addition of the organic halide to the $\operatorname{Pd}(0)$ species (Scheme 79). The allene would undergo carbopalladation of the species to generate a $\pi$-allylpalladium intermediate. Finally, the allylic compound is produced by nucleophilic attack.

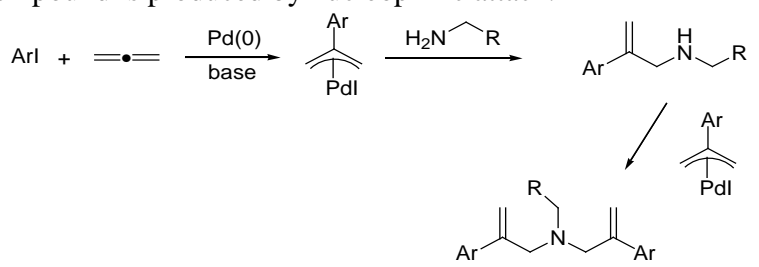

Scheme 79 Three-component reaction between allenes, amines and aryl iodides.

Based on this reactivity, it has been reported the synthesis of ten-membered heterocycles from 1,5-bis(allenes) via formation 45 of two $\pi$-allylic Pd intermediates, which may be trapped by a $\mathrm{NuH}_{2}$-type nucleophile. ${ }^{89}$ The first experiment consisted of treatment of bis(2,3-butadienyl)tosylamide 1a with iodobenzene in the presence of benzylamine, using $\mathrm{Pd}\left(\mathrm{PPh}_{3}\right)_{4}$ as catalyst (5 mol\%) and $\mathrm{K}_{2} \mathrm{CO}_{3}$ (4.0 equiv) as base in DMF as 50 solvent. The expected 10-membered ring 217a was isolated regio- and stereoselctively in $35 \%$ yield as single product (Scheme 82). After, testing the reaction with different catalyst and bases, the optimized reaction conditions were the use of $\mathrm{Pd}\left(\mathrm{PPh}_{3}\right)_{4}$ (5 mol\%), $\mathrm{Ag}_{3} \mathrm{PO}_{4}$ (0.7 equiv) and $\mathrm{K}_{3} \mathrm{PO}_{4}$ (1 equiv) 55 in DMF at $90^{\circ} \mathrm{C}$ (Scheme 80 ). The scope of the reaction was studied using different tethered 1,5-bis(allenes) $\mathbf{1}$, aryliodides and amines.

\footnotetext{
60 Scheme 80 Three-component reaction between 1,5-bis(allenes), amines and aryl iodides.
} 
The high regio- and stereoselectivity of this reaction has been explained via carbopalladation of one of the two allene groups in the substrate to form $\pi$-allylic Pd intermediate anti-218,

5 more favorable than syn-218 due to the steric interaction of the phenyl group $\mathrm{R}$ and the substituent containing the other allene group (Scheme 81). The regioselective intermolecular allylation takes place in anti-218 to form intermediate $\mathbf{2 1 9}$. Then, carbopalladation of the second allene moiety in the 10 substrate would favor the formation of $\pi$-allylic $\mathrm{Pd}$ intermediate anti-220. The regioselective intramolecular allylic substitution of anti-220 would lead to the formation of the tenmembered product 221.

\section{Conclusions}

15 In conclusion, the synthesis and reactivity of non-conjugated bis(allenes) studied so far showed the synthetic potential to obtain a high amount of different structures. Although, these days the reactivity of allenes is well developed and many applications to the synthesis of interesting molecules has been 20 achieved, bis(allenes) are promising molecules to organic chemists interested in the development of new synthetic methodologies. It is presumable that in the next few years we will observe how this family of bis(allenes) occupies an important role as starting materials or as in situ formed 25 intermediates, in the design of target compounds with potential therapeutic activities. Now, it is in our hands to investigate about the synthesis of highly different functionalized bis(allenes) as well as to study the reactivity of these molecules.

30

Scheme 81 Explanation for the selectivity observed in the threecomponent synthesis of adducts 221.

\section{${ }_{35}$ Abreviations}

$\begin{array}{ll}\text { Ac } & \text { acetyl } \\ \text { AIBN } & 2,2^{\prime} \text {-azobis(2-methylpropionitrile) } \\ \text { BQ } & \text { benzoquinone } \\ \text { Dba } & \text { dibenzylideneacetone }\end{array}$

$\begin{array}{ll}{ }_{40} \text { DCE } & \text { 1,2-dichloroethane } \\ \text { DBU } & \text { 1,8-diazabicycloundec-7-ene } \\ \text { DFT } & \text { density functional theory } \\ \text { DIB } & \text { dimethylformamide } \\ \text { DMSO } & \text { dimethylsulfoxide } \\ \text { 45 dppe } & \text { 1,2-bis(diphenylphosphino)ethane } \\ \text { dppp } & \text { 1,3-bis(diphenylphosphino)propane } \\ \text { EWG } & \text { electron withdrawing group } \\ \text { HQ } & \text { hydroquinone } \\ \text { NBS } & N \text {-bromosuccinimide } \\ \text { 50 NHC } & \text { N-heterocyclic carbene } \\ \text { NIS } & \text { N-iodosuccinimide } \\ \text { TBS } & t \text {-butyldimethylsilyl } \\ \text { TFP } & \text { tri(2'-furyl)phosphine } \\ \text { Ts } & p \text {-toluenesulfonyl }\end{array}$

\section{${ }_{55}$ Acknowledgements}

acknowledged.

(Project S2009/PPQ-1752) are gratefully

\section{${ }_{60}$ Notes and references}

${ }^{a}$ Grupo de Lactamas y Heterociclos Bioactivos, Departamento de Química Orgánica I, Unidad Asociada al CSIC, Facultad de Química, Universidad Complutense de Madrid, 28040 Madrid, Spain. Fax: +3491-3944103; E-mail: alcaideb@quim.ucm.es; 65 caragoncillo@quim.ucm.es

${ }^{b}$ Instituto de Química Orgánica General, IQOG-CSIC, Juan de la

Cierva 3, 28006 Madrid, Spain; E-mail: palmendros@iqog.csic.es

† Electronic Supplementary Information (ESI) available: [details of 70 any supplementary information available should be included here]. See DOI: $10.1039 / \mathrm{b} 000000 \mathrm{x} /$

\section{Notes and references}

1 For selected recent reviews about the chemistry of allenes, see: (a) Modern Allene Chemistry, ed. N. Krause and A. S. K. Hashmi,

75 Wiley-VCH: Weinheim, 2004; vol. 1-2. (b) T. Lechel, F. Pfrengle, H.-U. Reissig, R. Zimmer, ChemCatChem 2013, 5, 2100-2130. (c) S. Yu and S. Ma, Angew. Chem. Int. Ed., 2012, 51, 3074-3112. (d) P. Rivera-Fuentes, F. Diederich, Angew. Chem. Int. Ed., 2012, 51, 2818-2828. (e) N. Krause and C. Winter, Chem. Rev., 2011, 111,

80 1994-2009. (f) C. Aubert, L. Fensterbank, P. Garcia, M. Malacria, A. Simonneau, Chem. Rev., 2011, 111, 1954-1993. (g) B. Alcaide and P. Almendros Adv. Synth. Catal., 2011, 353, 2561-2576. (h) H. Kim and L. J. Williams, Curr. Opin. Drug Discovery Dev., 2008, 11, 870-894. (i) S. Ma, Chem. Rev., 2005, 105, 2829-2872. (j) R.

85 Zimmer, C. U. Dinesh, E. Nandanon, F. A. Khan, Chem. Rev. 2000, 100, 3067-3126.

2 A. Hoffmann-Röder and N. Krause, Angew. Chem. Int. Ed., 2004, 43, 1196-1216.

3 (a) K. M. Brummond and J. E. DeForrest, Synthesis, 2007, 90 795-818. (b) S. Yu and S. Ma, Chem. Commun., 2011, 47, 5384-5418.

4 (a) Hopf, H.; Markopoulus, G. Beilstein J. Org. Chem. 2012, 8 , 1936-1998. (b) Stamm, R.; Hopf, H. Beilstein J. Org. Chem. 2013, 9, 36-48.

955 Recently the research group of Ma has briefly highlighted the reactivity of 1,5-bis(allenes), see: G. Chen, X. Jiang, C. Fu and S. Ma, Chem. Lett., 2010, 39, 78-81.

6 For a recent review about catalytic cycloaddition reactions of allenes, see: F. López and J. L. Mascareñas, Chem. Eur. J., 2011, $100 \quad 17,418-428$. 
7 (a) P. Siengalewicz, J. Mulzer and U. Rinner, Eur. J. Org. Chem., 2011, 7041-7055.

8 (a) E. Lee-Ruff, G. Mladenova, Chem. Rev., 2003, 103, 1449-1484. (b) The Chemistry of Cyclobutanes, ed. Z. Rappoport and J. F. Liebman,; Wiley, 2005. (c) T. Seiser, T. Saget, D. N. Tran, N. Cramer, Angew. Chem. Int. Ed., 2011, 50, 7740-7752.

9 B. Alcaide, P. Almendros and C. Aragoncillo, Chem. Soc. Rev., 2010, 39, 783-816.

10 (a) R. Hoffmann and R. B. Woodward J. Am. Chem. Soc., 1965,

10 87, 2046-2048. (b) R. B. Woodward and R. Hoffmann, Angew. Chem. Int. Ed. Engl., 1969, 8, 781-853.

11 S. Inagaki, H. Fujimoto and K. Fukui, J. Am. Chem. Soc., 1976, 98 , 4693-4701.

12 X. Jiang, X. Cheng, and S. Ma, Angew. Chem. Int. Ed., 2006, 45, 8009-8013.

13 S. Kitagaki, M. Kajita and C. Mukai Org. Lett., 2012, 14, 1366-1369.

14 F. Toda, K. Tanaka, I. Sano, T. Isozaki, Angew. Chem. Int. Ed., Engl. 1994, 33, 1757-1758.

2015 J. Inanaga, Y. Sugimoto and T. Hanamoto, Tetrahedron Lett., 1992, 33, 7035-7038.

16 K. Tanaka, N. Takamoto, Y. Tezuka, M. Kato and F. Toda, Tetrahedron, 2001, 57, 3761-3767.

17 (a) S. Kitagaki, Y. Okumara and C. Mukai, Tetrahedron Lett., 2006, 47, 1849-1852. (b) S. Kitagaki, Y. Okumara and C. Mukai, Tetrahedron, 2006, 62, 10311-10320.

18 C. Delas, H. Urabe and F. Sato Tetrahedron Lett., 2001, 42, 4147-4150.

19 M. Chen, J. Liu, L. Wang, X. Zhou and Y. Liu, Chem. Commun. 2013, 49, 8650-8652.

20 B. Alcaide, P. Almendros and C. Aragoncillo, Chem. Eur. J., 2009, 15, 9987-9989.

21 B. Alcaide, P. Almendros, C. Aragoncillo and G. GómezCampillos, Eur. J. Org. Chem., 2011, 364-370.

3522 (a) T. Shibata, Adv. Synth. Catal., 2006, 348, 2328-2336. (b) L. V. R. Boñaga and M. E. Krafft, Tetrahedron, 2004, 60, 9795-9833. (c) J. Blanco-Urgoiti, L. Añorbe, L. Pérez-Serrano, G. Dominguez and J. Pérez-Castells, Chem. Soc. Rev., 2004, 33, 32-42.

23 For a review, see: B. Alcaide and P. Almendros, Eur. J. Org.

$40 \quad$ Chem., 2004, 3377-3383.

24 (a) F. Inagaki, S. Narita, T. Hasegawa, S. Kitagaki and C. Mukai, Angew. Chem. Int. Ed., 2009, 48, 2007-2011. (b) T. Kawamura, F. Inagaki, S. Narita, Y. Takahashi, S. Hirata, S. Kitagaki and C. Mukai, Chem. Eur. J., 2010, 16, 5173-5183.

4525 M. T. S. Shafawati, F. Inagaki, T. Kawamura and C. Mukai, Tetrahedron, 2013, 69, 1509-1515.

26 (a) H. Cao, J. Flippen-Anderson and J. M. Cook, J. Am. Chem. Soc., 2003, 125, 3230-3231. (b) H. Cao, S. G. Van Ornum, J. Deschamps, J. Flippen-Anderson, F. Laib and J. M. Cook, J. Am. Chem. Soc., 2005, 127, 933-943.

27 G. Schön and H. Hopf, Liebigs Ann. Chem., 1981, 165-180.

28 D. J. Pasto and S.-H. Yang, J. Org. Chem., 1989, 54, 3978-3981.

29 S. Kitagaki, K. Ohdachi, K. Katoh and C. Mukai, Org. Lett., 2006, 8, 95-98.

${ }_{55} 30$ H. Yu and P. H. Lee, J. Org. Chem., 2008, 73, 5183-5186.

31 I. P. Beletskaya and V. P. Ananikov, Chem. Rev., 2011, 111, 1596-1636.

32 P. Lu and S. Ma, Org. Lett., 2007, 9, 2095-2097.

33 P. Lu, J. Kuang and S. Ma, Synlett, 2010, 227-230.

6034 S. Ma, P. Lu, L. Lu, H. Hou, J. Wei, Q. He, Z. Gu, X. Jiang, X. Jin, Angew. Chem. Int. Ed., 2005, 44, 5275-5278.

35 S. Ma and L. Lu, Chem. Asian J., 2007, 2, 199-204.

36 P. Lu and S. Ma, Org. Lett., 2007, 9, 5319-5321.

37 Z. Gu, X. Wang, W. Shu, S. Ma, J. Am. Chem. Soc., 2007, 129, 10948-10956.

38 X. Lian and S. Ma, Chem. Eur. J., 2010, 16, 7960-7964.

39 Multicomponent Reactions, ed. J. Zhu and H. Bienaymé, Wiley: Weinheim, 2005

40 B. B. Touré and D. G. Hall, Chem. Rev., 2009, 109, 4439-4486.

7041 C. Kalinski, H. Lemoine, J. Schmidt, C. Burdack, J. Kolb, M. Umkehrer and G. Ross, Synthesis, 2008, 4007-4011.
42 S. Ma and A. Zhang, J. Org. Chem., 2002, 67, 2287-2294.

43 W. Shu, G. Jia and S. Ma, Angew. Chem. Int. Ed., 2009, 48, 2788-2791.

7544 J. Ye and S. Ma, Angew. Chem. Int. Ed. 2013, 52, 10809-10813.

45 M. Chen, Y. Chen and Y. Liu, Chem. Commun. 2012, 48 , 12189-12191.

46 S.-K. Kang, T.-G. Baik, A. N. Kulak, Y.-H. Ha, Y. Lim, Y. and J. Park, J. Am. Chem. Soc., 2000, 122, 11529-11530.

8047 Y. T. Hong, S.-K. Yoon, S.-K. Kang and C. M. Yu, Eur. J. Org Chem., 2004, 4628-4635.

48 For recent reviews on the chemistry of gold catalysts, see: (a) A. S. K. Hashmi and G. J. Hutchings, Angew. Chem. Int. Ed., 2010, 49, 5232-5241. (b) Chem. Rev., 2008, 108, issue 8, ed. B. Lipshutz and Y. Yamamoto.

49 S. M. Kim, J. H. Park, S. Y. Choi and Y. K. Chung, Angew. Chem. Int. Ed., 2007, 46, 6172-6175.

50 S. M. Kim, J. H. Park, Y. K. Kang and Y. K. Chung, Angew. Chem. Int. Ed., 2009, 48, 4532-4535.

9051 For a recent review, see: (a) S. P. Nolan and H. Clavier Chem. Soc. Rev., 2010, 39, 3305-3316. For the application of metathesis reaction in natural product synthesis, see: (b) J. Prunet, Eur. J. Org. Chem., 2011, 3634-3647. (c) Metathesis in Natural Product Synthesis, ed. J. Cossy, S. Arseniyadis, C. Meyer and R. H. Grubbs

95 Wiley-VCH: Weinheim, 2010.

52 M. Ahmed, T. Arnauld, A. G. M. Barrett, D. C. Braddock, K. Flack and P. A. Procopiou, A. Org. Lett., 2000, 2, 551-553.

53 C. E. Janßen and N. Krause, Eur. J. Org. Chem., 2005, 2322-2329.

10054 (a) D. T. Craft and B. W. Gung, Tetrahedron Lett., 2008, 49, 5931-5934. (b) B. W. Gung, D. T. Craft, Tetrahedron Lett., 2009, 50, 2685-2687.

55 G. J. Rowlands, Tetrahedron, 2010, 66, 1593-1636.

56 (a) B. Alcaide, P. Almendros and C. Aragoncillo Org. Lett., 2003,

105 5, 3795-3798. (b) B. Alcaide, P. Almendros, C. Aragoncillo and M. C. Redondo J. Org. Chem., 2007, 72, 1604-1608.

57 S.- K.Kang,Y.-H. Ha, D.-H. Kim, Y. Lim and J. Jung, Chem. Commun., 2001, 1306-1307.

58 R. Mukherjee and A. Basak, Synlett, 2012, 23, 877-880.

11059 S. Mondal, A. Basak, S. Jana, A. Anoop, Tetrahedron, 2012, 68, 7202-7210.

60 B. Alcaide, P. Almendros, J. M. Alonso, M. T. Quirós and P. Gadziński, Adv. Synth. Catal., 2011, 353, 1871-1876.

61 (a) C. Fu, J. Li, S. Ma, Chem. Commun., 2005, 4119-4121. (b) J.

$115 \mathrm{Li}, \mathrm{C} . \mathrm{Fu}, \mathrm{G}$. Chen, G. Chai, G. and S. Ma, Adv. Synth. Catal., 2008, 350, 1376-1382.

62 B. Alcaide, P. Almendros, A. Luna, S. Cembellín, M. Arnó and M; L. R. Domingo, Chem. Eur. J., 2011, 17, 11559-11566.

63 S. Ma, Acc. Chem. Res., 2003, 36, 701-712.

12064 R. W. Bates and V. Satcharoen, Chem. Soc. Rev., 2002, 31, 12-21.

65 H. Heaney, and J. S. Ahn, in Comprehensive Heterocyclic Chemistry II; ed. A. R. Katritzky, C. W. Rees and E. F. V. Scriven, Pergamon Press: Oxford, 1996; vol. 2, 297-436.

66 T. G. Kilroy, T. P. O’Sullivan and P. J. Guiry, Eur. J. Org. Chem., $125 \quad 2005,4929-4949$.

67 N. Krause, M. Laux and A. Hoffmann-Röder, Tetrahedron Lett., 2000, 41, 9613-9616.

68 L.-I. Olsson and A. Claesson, Synthesis, 1979, 743-745.

69 J. A. Marshall and K. G. Pinney, J. Org. Chem., 1993, 58, $7180-7184$

70 J. A. Marshall and G. S. Bartley, J. Org. Chem., 1994, 59, 7169-7171.

71 A. Hoffmann-Röder and N. Krause, Org. Lett., 2001, 3, 2537-2538.

13572 N. Krause, A. Hoffmann-Röder and J. Canisius, J. Synthesis, 2002, 1759-1774.

73 C. Deutsch, B. Gockel, A. Hoffmann-Röder and N. Krause, Synlett, 2007, 1790-1794

74 A. S. K. Hashmi, T. L. Ruppert, T. Knöfel and J. W. Bats, J. Org. Chem., 1997, 62, 7295-7304.

75 M. Poonoth and N. Krause, Adv. Synth. Catal., 2009, 351, $117-122$. 
76 S. Ma and Z. Gu, J. Am. Chem. Soc., 2005, 127, 6182-6183.

77 B. Alcaide, P. Almendros and T. Martínez del Campo, Angew. Chem. Int. Ed., 2006, 45, 4501-4504.

78 B. Alcaide, P. Almendros, T. Martínez del Campo and R.

5 Carrascosa, Chem. Asian J., 2008, 3, 1140-1145.

79 Y. Deng, J. Li and S. Ma, Chem. Eur. J., 2008, 14, 4263-4266.

80 Y. Deng, J. Li and S. Ma, J. Org. Chem., 2008, 73, 585-589.

81 B. Alcaide, P. Almendros and T.Martínez del Campo, Chem. Eur. J., 2010, 16, 5836-5842.

1082 Y. Deng, Y. Shi and S. Ma, Org. Lett., 2009, 11, 1205-1208.

83 (a) A. S. K. Hashmi, T. L. Ruppert, T. Knöfel and J. W. Bats, J. Org. Chem., 1997, 62, 7295-7304. (b) A. S. K. Hashmi, Angew. Chem. Int. Ed., 1995, 34, 1581-1583.

84 B. Alcaide, P. Almendros and T. Martinez del Campo Eur. J. Org. 15 Chem., 2007, 2844-2849.

85 Y. Deng, C. Fu and S. Ma, Chem. Eur. J., 2011, 17, 4976-4980.

86 For selected reviews, see: (a) A. Sharma, P. Appukkuttan and E. Van der Eycken, Chem. Commun., 2012, 48, 1623-1637. (b) L. Yet, Chem. Rev., 2000, 100, 2963-3008.

2087 (a) M. W. van Laren, J. J. H. Diederen and C. J. Elsevier, Adv. Synth. Catal., 2001, 343, 255-259. (b) X. Gai, R. Grigg, S. Collard and J. E. Muir, Chem. Commun., 2001, 1712-1713. (c) R. Grigg, T. Khammaen, S. Rajviroongit, V. Sridharan, Tetrahedron Lett., 2002, 43, 2601-2603.

2588 R. Grigg, I. Köppen, M. Rasparini and V. Sridharan, Chem. Commun., 2001, 964-965.

89 J. Cheng, X. Jiang and S. Ma, Org. Lett., 2011, 13, 5200-5203.

30
Autores: Alcaide, B.; Almendros, P.; Aragoncillo, C.

${ }_{35}$ Título: Cyclization Reactions of Bis(allenes) for the Synthesis of Polycarbo(hetero)cycles

Revista: Chem. Soc. Rev. 2014, 43, 3106-3135;
DOI: $10.1039 /$ C3CS60462D

40 